Article

\title{
Effect of $\alpha^{\prime}$ Martensite Content Induced by Tensile Plastic Prestrain on Hydrogen Transport and Hydrogen Embrittlement of 304L Austenitic Stainless Steel
}

\author{
Yanfei Wang ${ }^{1, *}$, Xuanpei $\mathrm{Wu}^{1}$ and Weijie $\mathrm{Wu}^{2}$ \\ 1 School of Chemical Engineering \& Technology, China University of Mining and Technology, \\ Xuzhou 221116, China; wxp_hg@126.com \\ 2 School of Mechanical and Power Engineering, Nanjing Tech University, Nanjing 211816, China; \\ stephen_nj@163.com \\ * Correspondence: wyf709903@163.com; Tel.: +86-516-8359-1060
}

Received: 24 July 2018; Accepted: 20 August 2018; Published: 23 August 2018

\begin{abstract}
Effects of microstructural changes induced by prestraining on hydrogen transport and hydrogen embrittlement (HE) of austenitic stainless steels were studied by hydrogen precharging and tensile testing. Prestrains higher than $20 \%$ at $20{ }^{\circ} \mathrm{C}$ significantly enhance the $\mathrm{HE}$ of $304 \mathrm{~L}$ steel, as they induce severe $\alpha^{\prime}$ martensite transformation, accelerating hydrogen transport and hydrogen entry during subsequent hydrogen exposure. In contrast, $304 \mathrm{~L}$ steel prestrained at 50 and $80{ }^{\circ} \mathrm{C}$ and 316L steel prestrained at $20^{\circ} \mathrm{C}$ exhibit less HE, due to less $\alpha^{\prime}$ after prestraining. The increase of dislocations after prestraining has a negligible influence on apparent hydrogen diffusivity compared with pre-existing $\alpha^{\prime}$. The deformation twins in heavily prestrained 304L steel can modify HE mechanism by assisting intergranular (IG) fracture. Regardless of temperature and prestrain level, $\mathrm{HE}$ and apparent diffusivity $\left(D_{\text {app }}\right)$ increase monotonously with $\alpha^{\prime}$ volume fraction $\left(f_{\alpha^{\prime}}\right)$. $D_{\text {app }}$ can be described as $\log D_{\text {app }}=\log \left(D_{\alpha^{\prime}} s_{\alpha^{\prime}} / s_{\gamma}\right)+\log \left[f_{\alpha^{\prime}} /\left(1-f_{\alpha^{\prime}}\right)\right]$ for $10 \%<f_{\alpha^{\prime}}<90 \%$, with $D_{\alpha^{\prime}}$ is diffusivity in $\alpha^{\prime}, s_{\alpha^{\prime}}$ and $s_{\gamma}$ are solubility in $\alpha^{\prime}$ and austenite, respectively. The two equations can also be applied to these more typical duplex materials containing both BCC and FCC phases.
\end{abstract}

Keywords: hydrogen embrittlement; stainless steel; deformation; martensite transformation

\section{Introduction}

Many studies have focused on the effects of microstructural changes induced by prior plastic deformations on the hydrogen embrittlement (HE) and hydrogen transport of austenite stainless steels (ASSs) [1-11], considering that ASS components often suffer from some degrees of plastic deformations during manufacturing processes before hydrogen exposure. In metastable ASSs, the microstructural changes mainly include the increase of dislocation density, formation of deformation twins and transformation from $\gamma$ austenite to $\alpha^{\prime}$ martensite.

Some studies have demonstrated that $\alpha^{\prime}$ platelets induced by prior deformations (pre-existing $\alpha^{\prime}$ ) can increase significantly HE of ASSs because they accelerate hydrogen transport [1-4,9-11] during hydrogen exposure by acting as diffusion "highways". The hydrogen diffusivity has been found 5-6 orders of magnitude higher in $\alpha^{\prime}$ than in $\gamma$. For example, Perng and Altstetter [1] showed that the apparent hydrogen diffusivity and permeability in 301 and 304 steels were greatly increased by pre-existing $\alpha^{\prime}$. In contrast, up to $80 \%$ deformation of 310 steel made only small changes in these two parameters, since no $\alpha^{\prime}$ was pre-introduced. Mine et al. [2] found that, for 304 steel, in which prestrain-induced $\alpha^{\prime}$ was detected, fatigue crack growth (FCG) rate was more sensitive to hydrogen in prestrained steel than in solution-annealed steel. The increases of dislocations and other lattice defects after prestraining increased apparent solubility but without affecting diffusivity. In 316L steel, 
which exhibited little $\alpha^{\prime}$ after prestraining, there was no significant difference in FCG rate between the uncharged and hydrogen-charged specimens. Martin et al. [3] even revealed a detrimental effect of machining-induced $\alpha^{\prime}$ on the performance of 304 steel after hydrogen exposure.

Dislocations can act as trap sites for hydrogen, thus the increase of dislocations after prestraining increases the apparent hydrogen solubilities of both ferritic steels and ASSs $[1,2,12,13]$. But it does not reduce the apparent diffusivity of ASSs [1,2], contrary to ferritic steels [12,13]. Mine et al. [2] explained this as that the binding energy of hydrogen to dislocations in face-centered cubic (FCC) $\gamma$ is not higher than the activation energy of lattice diffusion of hydrogen, whereas in body-centered cubic (BCC) ferrite the binding energy of hydrogen to dislocations is higher. However, Michler et al. [14] studied the HE of ASSs, which were firstly deformed to various strains at various low temperatures to result in different pre-existing $\alpha^{\prime}$ contents and initial dislocation densities and then were tensile tested to failure in gaseous hydrogen. They found that HE increased with increasing initial dislocation density rather than with $\alpha^{\prime}$ content. They explained this by the fact that hydrogen can be transported by dislocation movement during plastic deformation [15]. The dislocation density increased as prestrain level increased, consequently, a higher amount of hydrogen was carried and transported from the external hydrogen gas into the interior of steel during deformation, leading to more severe HE. But when the initial dislocation density was increased to exceed a "critical" value, HE started to decrease, as in the heavily prestrained steel the mean free path of dislocations was too low to provide a sufficient transport distance and thus to cause HE effect. They concluded that, in the HE of ASSs loading directly in gaseous hydrogen, the initial dislocation density played a more crucial role than the pre-existing $\alpha^{\prime}$, though they did not exclude the role of pre-existing $\alpha^{\prime}$.

Twins play an important role in HE of twinning-induced plasticity (TWIP) steels [16-18], because on one hand, stress concentrations can arise at the tips of twin plates, and on the other hand twin boundaries have higher binding energy with hydrogen compared with dislocations, thus they can trap and accumulate hydrogen strongly. Under the combined effect of stress concentration and hydrogen accumulation, hydrogen-assisted cracking initiates preferentially at twin tips and crack propagation occurs along twin boundaries. In addition, it is shown that in TWIP steels the presence of twins can even assist intergranular (IG) fracture [16-18]. In 300 series ASSs, twins also play a role. As known, hydrogenated ASSs often show some flat facets in their fracture surfaces, which is believed to be caused by hydrogen-assisted cracking along the boundaries of annealing twins [2,4,7-9,19-21]. The effect of prestrain and its induced deformation twins on the HE of ASSs has been especially studied by Ji et al. [22,23]. In $310 \mathrm{~S}$ steel, they found that prestrains and pre-existing deformation twins suppressed both the formation of fresh deformation twins and the delivery of hydrogen to twin boundaries during deformation, as a result with increasing prestrain level HE decreased [22]. Nevertheless, for 316L steel, although prestrains suppressed the formation of fresh deformation twins, they increased the volume fraction of $\varepsilon$ martensite and consequently caused the segregation of hydrogen to $\gamma / \varepsilon$ interfaces, resulting in increasing HE with increasing prestrain [23]. Recently, Chen et al. [9] studied the effects of $\alpha^{\prime}$ and deformation twins on hydrogen-assisted FCG of cold- and warm-rolled 304 steel. In cold-rolled 304 steel, FCG was accelerated significantly by $\alpha^{\prime}$ platelets pre-induced by cold-rolling. However, for warm-rolled 304 steel, in which almost no $\alpha^{\prime}$ phase existed, FCG rate was controlled by deformation twins induced by warm-rolling. FCG rate was enhanced by hydrogen-assisted cracking along deformation twin boundaries and slip bands, though the enhancement degree was less compared with $\alpha^{\prime}$ platelets in cold-rolled steel.

As known, depending on the original location of hydrogen, HE can be classified into internal HE (IHE) and hydrogen environment embrittlement (HEE). Clearly, the HE type investigated by Michler et al. [14] is HEE. Since there are often significant differences between IHE and HEE, in this study we investigated the effect of prestraining on hydrogen transport and IHE of metastable 304L steel. By altering prestrain level and temperature at which a prestrain was applied, different fractions of $\alpha^{\prime}$ were pre-introduced into the 304L steel [24-26]. Prestrains also varied twin morphology and dislocation density. The HE was then evaluated by electrochemical hydrogen precharging and tensile 
testing. To differentiate the effect of the pre-existing $\alpha^{\prime}$ from that of the dislocation density on the resulting HE degree and hydrogen transport, the more stable 316L steel was also tested. In the 316L steel, prestrains can result in an increase of dislocation density but cannot induce severe $\alpha^{\prime}$ transformation. The resulting HE degree and apparent transport parameters (i.e., diffusivity and solubility) were related to these microstructural changes to demonstrate their effects. In addition, quantitative analyzes on the hydrogen transport parameters as a function of pre-existing $\alpha^{\prime}$ content were also performed by both theoretical analysis and finite element (FE) simulations.

\section{Materials and Methods}

\subsection{Materials and Specimens}

Industrially hot-rolled 304L and 316L plates with chemical compositions listed in Table 1 were used. They were solution-annealed at $1080{ }^{\circ} \mathrm{C}$ for $1 \mathrm{~h}$ and water-quenched. $\mathrm{Md}_{30}$, i.e., the temperature at which straining to $30 \%$ induces $50 \%$ vol. $\alpha^{\prime}$, is 25 and $-62{ }^{\circ} \mathrm{C}$ for the $304 \mathrm{~L}$ and $316 \mathrm{~L}$ steel, respectively, according to the formula proposed by Nohara et al. [27]: $\mathrm{Md}_{30}\left({ }^{\circ} \mathrm{C}\right)=551-462(\mathrm{C}+\mathrm{N})-9.2 \mathrm{Si}-$ $8.1 \mathrm{Mn}-29(\mathrm{Ni}+\mathrm{Cu})-13.7 \mathrm{Cr}-18.5 \mathrm{Mo}-1.42(d-8)(\mathrm{wt} . \%, d$ is the ASTM grain size grade, which is 5.0 and 5.5 for the 304L and 316L, respectively, based on ASTM E112 standard [28]). Thus, the 304L steel used is metastable at room temperature but the $316 \mathrm{~L}$ steel is stable. Tensile specimens with a gauge size of 25 (length) $\times 10$ (width) $\times 2$ (thickness) $\mathrm{mm}^{3}$ were cut from the plates with length direction parallel to rolling direction. The specimen surfaces were ground with successive grades of emery paper up to 2000 grit and then were polished with paste, washed with deionized water and dried.

Table 1. Chemical compositions of the 304L and 316L ASSs used (in wt.\%).

\begin{tabular}{ccccccccccc}
\hline Material & $\mathbf{C}$ & $\mathbf{S i}$ & $\mathbf{M n}$ & $\mathbf{S}$ & $\mathbf{P}$ & $\mathbf{C r}$ & $\mathbf{M o}$ & $\mathbf{N i}$ & $\mathbf{C u}$ & $\mathbf{N}$ \\
\hline 304L & 0.020 & 0.37 & 1.15 & 0.004 & 0.031 & 18.30 & 0.01 & 8.10 & 0.064 & 0.044 \\
316L & 0.017 & 0.34 & 1.15 & 0.002 & 0.030 & 16.78 & 2.20 & 10.23 & 0.323 & 0.043 \\
\hline
\end{tabular}

\subsection{Prestraining}

Uniaxial plastic prestrains were introduced by tensile at a strain rate of $2.5 \times 10^{-4} \mathrm{~s}^{-1}$ using a tensile machine with a heating furnace. It has been found that, near $\mathrm{Md}_{30}$ temperature, elevating the temperature even slightly can lead to a rapid reduction in $\alpha^{\prime}$ content [24-26]. Thus, the temperatures at which prestrains were applied for $304 \mathrm{~L}$ steel included both room temperature $\left(20^{\circ} \mathrm{C}\right)$ and higher temperatures $\left(50\right.$ and $\left.80^{\circ} \mathrm{C}\right)$. The specimens were heated slowly $\left(\sim 5{ }^{\circ} \mathrm{C} / \mathrm{min}\right)$ to the specified temperatures and then clamped and tensioned to deform plastically. The temperature used for $316 \mathrm{~L}$ steel was $20^{\circ} \mathrm{C}$; at this temperature the $316 \mathrm{~L}$ steel is stable against $\alpha^{\prime}$ transformation. The plastic prestrain levels were set as $10( \pm 1), 20( \pm 2), 30( \pm 2)$, and $40( \pm 3) \%$ for each temperature. After cooling, the resulting prestrain levels were measured. If the measured prestrain value of a specimen fell into the above specified tolerance interval, the specimen was used, otherwise, was abandoned.

\subsection{Microstructural Examinations}

To reveal the microstructural changes after prestraining, the un-prestrained and prestrained specimens were examined by an optical microscope (OM, AXIO Imager.A1m, ZEISS, Oberkochen, Germany) after etching by Beraha's tint reagent $(0.5 \mathrm{~g}$ potassium metabisulfite, $20 \mathrm{~mL} \mathrm{HCl}$ and $100 \mathrm{~mL}$ distilled water), which can etch and reveal clearly the $\alpha^{\prime}$ platelets (dark) and austenite phase (white) by color difference [29-31]. Some specimens are also examined by an electron backscattered diffraction (EBSD) detector (NordlysNano, OXFORD, Oxford, UK) after grounding and vibration polishing for $12 \mathrm{~h}$. Channel 5 HKL software package was used to analyze and display EBSD data. In the generated orientation imaging microscopy (OIM) maps, different colors are used for ordinary high angle boundaries (misorientations greater than $15^{\circ}$ ), low angle boundaries (misorientations less than $15^{\circ}$ ), and $\Sigma 3$ boundaries (misorientation 
of $60^{\circ}$ about a $<111>$ axis). $\Sigma 3$ boundaries are considered as the twin boundaries [32] to reveal the presence of twins. The BCC phase was also detected by the EBSD.

\subsection{Martensite Content and Dislocation Density Measurements}

To quantitatively determine $\alpha^{\prime}$ contents induced, the volume fractions of ferromagnetic phase was measured by a calibrated Feritscope (MF300F+, DIVERSE, Cambridge, UK), which is based on magnetic induction, giving the average ferromagnetic phase content yielding from a certain volume at measured site. Since $\gamma$ is not ferromagnetic, the ferromagnetic phase can be taken as $\alpha^{\prime}[4,7,8]$. To verify the Feritscope readings, phase identifications and estimations were also carried out by X-ray diffraction (XRD) on un-prestrained and 30\% prestrained specimens. The XRD was conducted by a diffractometer (SmartLab, RIGAKU, Tokyo, Japan) at $20^{\circ} \mathrm{C}$ using a Cu-K $\alpha(\lambda=0.154056 \mathrm{~nm})$ radiation operating at $40 \mathrm{kV}$ and $30 \mathrm{~mA}$ at a step size of $0.02^{\circ}$. The quantitative estimations of phase fractions are based on the principle that the total integrated intensity of all diffraction peaks for each phase in a mixture is proportional to the volume fraction of that phase [33,34]. That is, the volume fractions of $\gamma, \alpha^{\prime}$, and $\varepsilon$ can be derived by considering $(220)_{\gamma},(311)_{\gamma},(111)_{\gamma}$, and (200) $\gamma_{\gamma}$ reflections for FCC $\gamma$ austenite, $(200)_{\alpha^{\prime}}$, $(211)_{\alpha^{\prime}}$, and $(110)_{\alpha^{\prime}}$ reflections for BCC $\alpha^{\prime}$ martensite, $(101)_{\varepsilon}$ and $(102)_{\varepsilon}$ for HCP $\varepsilon$ martensite by the following formula:

$$
V_{i}=\frac{\frac{1}{n} \sum_{j=1}^{n} I_{i}^{j} / R_{i}^{j}}{\frac{1}{n} \sum_{j=1}^{n} I_{\gamma}^{j} / R_{\gamma}^{j}+\frac{1}{n} \sum_{j=1}^{n} I_{\alpha^{\prime}}^{j} / R_{\alpha^{\prime}}^{j}+\frac{1}{n} \sum_{j=1}^{n} I_{\varepsilon}^{j} / R_{\varepsilon}^{j}}
$$

where $i=\gamma, \alpha^{\prime}$ or $\varepsilon, n$ is number of peaks of phase examined, $I_{i}$ and $R_{i}$ are integrated intensity of reflecting plane and material scattering factor, respectively. Each $R_{i}$ value was taken from [33].

Dislocation density were evaluated based on the method of Williamson-Hall $[35,36]$ using the XRD patterns. This method calculates dislocation density, $\rho_{d}$, from the average values of microstrain, $\left\langle\varepsilon^{2}\right\rangle^{1 / 2}$, and crystallite size, $d$, of material by

$$
\rho_{d}=\frac{3 \sqrt{2 \pi}\left\langle\varepsilon^{2}\right\rangle^{1 / 2}}{d b}
$$

where $b$ is the Burgers vector, $b=a / \sqrt{2}$ for the FCC structure with $a$ is the lattice parameter. The determinations of $\left\langle\varepsilon^{2}\right\rangle^{1 / 2}$ and $d$ by using the XRD patterns have been reported elsewhere [35]. Although the Williamson-Hall method is not the most precise method to determine the dislocation density, it is enough to identify the changing trend of dislocation density [14,37].

\subsection{Hydrogen Precharging and Total Hydrogen Amount Measurements}

Hydrogen charging was performed in $0.1 \mathrm{~mol} / \mathrm{L} \mathrm{NaOH}$ solution for $48 \mathrm{~h}$ at $50{ }^{\circ} \mathrm{C}$ using a current density of $1.1 \mathrm{~mA} / \mathrm{cm}^{2}$. Specimens were cathodes and Pt sheets were anodes. After charging, one group of specimens was taken to tensile testing immediately (within $5 \mathrm{~min}$ ). To examine the hydrogen uptake during charging, the other group of specimens were selected to measure the total hydrogen amount charged into using an oxygen-nitrogen-hydrogen analyzer (ONH836, LECO, St. Joseph, MI, USA), which melted the specimens and measured the total mass of released hydrogen, $m_{H}$, through the inert gas impulse fusion heat conductivity method [38].

\subsection{Tensile Testing and HE Degree Evaluation}

Tensile testing after charging was performed at $20^{\circ} \mathrm{C}$ also at the strain rate of $2.5 \times 10^{-4} \mathrm{~s}^{-1}$. The uncharged un-prestrained and prestrained specimens were also tested as references. Tensile properties including yield strength $(0.2 \%$ flow stress), tensile strength, and total elongation were recorded. To quantitatively describe the $\mathrm{HE}$ degree, $\mathrm{HE}$ index $\delta_{\mathrm{L}}$, i.e., plasticity loss was used as

$$
\delta_{\mathrm{L}}=\left(\delta_{0}-\delta_{\mathrm{H}}\right) / \delta_{0}
$$


where $\delta_{0}$ and $\delta_{\mathrm{H}}$ are the total elongation of uncharged and charged specimen, respectively. HE degree increases with increasing $\delta_{\mathrm{L}}$. Fracture surfaces of broken specimens were examined by a scanning electron microscope (SEM, JSM-6510, JEOL, Tokyo, Japan). The apparent diffusivity and solubility of hydrogen was evaluated by analyze the brittle fracture region depth of fracture surfaces using Fick's law. For $30 \%$ prestrain, two duplicate specimens were tested for each prestrain temperature.

\section{Results}

\subsection{Martensite Transformation and Microstructures}

The results of $\alpha^{\prime}$ content and OM images are shown in Figures 1-3 Almost no $\alpha^{\prime}$ was detected in un-prestrained 304L and 316L steels, Figures 1 and 2, indicating that both steels without prestraining were fully austenitic. The OM images confirm this, as the two steels exhibit typical microstructures of solution-annealed 300 series ASSs, i.e., consisting of nearly-equiaxed $\gamma$ grains and some annealing twins, Figure 3a,g. However, as expected, the $304 \mathrm{~L}$ steel prestrained at $20^{\circ} \mathrm{C}$ exhibit $\alpha^{\prime}$, particularly at prestrains higher than $20 \%$, as shown by Feritscope readings, Figure 1, and the presence of (110), (200), and (211) $\alpha^{\prime}$ peaks in XRD patterns, Figure 2a $\alpha^{\prime}$ content increases with prestrain. The $\alpha^{\prime}$ content is $41.5 \%$ in $30 \%$ prestrained specimens whereas it is $67.9 \%$ in $40 \%$ prestrained specimens. The OM images confirm the presence of a large fraction of $\alpha^{\prime}$ in the heavily prestrained 304L specimens, as etched dark platelets appeared within the bunches of shear bands, Figure 3b-d [29-31]. Thus, a high level of prestrain $(>20 \%)$ near $20^{\circ} \mathrm{C}$ can induce severe $\alpha^{\prime}$ transformation in $304 \mathrm{~L}$ steel due to its higher $\mathrm{Md}_{30}$ temperature. In contrast, $316 \mathrm{~L}$ steel exhibits only a little $\alpha^{\prime}$ even at $40 \%$ prestrain at $20^{\circ} \mathrm{C}(2.6 \%)$, Figure 1, Figure $2 b$, and Figure $3 \mathrm{~h}$, because it is stable.

Turning to 304L specimens prestrained at higher temperatures, Figure 1 shows that, the specimens prestrained at $50{ }^{\circ} \mathrm{C}$ exhibit less $\alpha^{\prime}$ (for example, almost no $\alpha^{\prime}$ at $10 \%$ prestrain, $15.7 \% \alpha^{\prime}$ at $40 \%$ prestrain) and the specimens prestrained at $80{ }^{\circ} \mathrm{C}$ exhibit almost no $\alpha^{\prime}$ at all prestrain levels (for example, $1.2 \% \alpha^{\prime}$ at $40 \%$ prestrain at $80^{\circ} \mathrm{C}$ ). The XRD patterns, Figure $2 \mathrm{a}$, and OM images, Figure $3 \mathrm{e}, \mathrm{f}$, also indicate that there is only a small content of $\alpha^{\prime}$ in the specimens prestrained at $50^{\circ} \mathrm{C}$ and almost no $\alpha^{\prime}$ in the specimens prestrained at $80^{\circ} \mathrm{C}$. Clearly, the results confirm that, increasing the prestrain temperature to slightly higher than $\mathrm{Md}_{30}$ temperature can rapidly suppress $\alpha^{\prime}$ transformation upon prestraining for $304 \mathrm{~L}$ steel, in line with previous studies [24-26]. The higher the temperature used, the more significantly the transformation is suppressed.

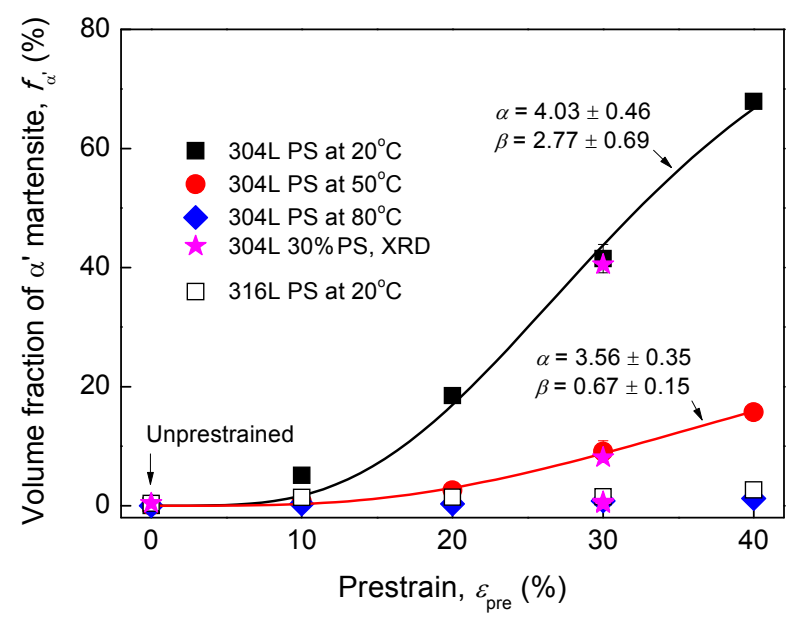

Figure 1. Volume fraction of $\alpha^{\prime}$ obtained by Feritscope for 304L and 316L specimens un-prestrained and prestrained (PS) at different temperatures. The fitting curves based on the relation proposed by Olson and Cohen [39] are also depicted: $f_{\alpha^{\prime}}=1-\exp \left\{-\beta\left[1-\exp \left(-\alpha \varepsilon_{\text {pre }}\right)\right]^{n}\right\}$, where $n$ is a fixed exponent having a value of 4.5 , and $\alpha$ and $\beta$ are temperature-dependent parameters, which decrease with increasing temperature, in agreement with [39]. 

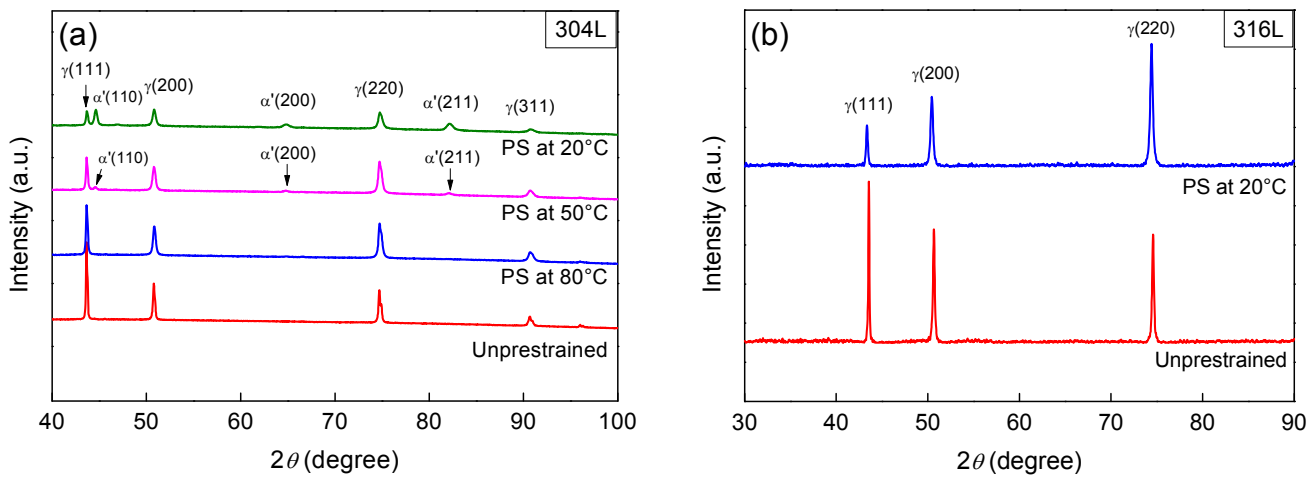

Figure 2. XRD patterns of 304L (a) and 316L (b) steel specimens un-prestrained and prestrained (PS) to $30 \%$ strain at different temperatures. The $(220) \gamma$ reflection becomes dominant after prestraining, indicating that texture changes also occur due to the uniaxial tensile prestrain.
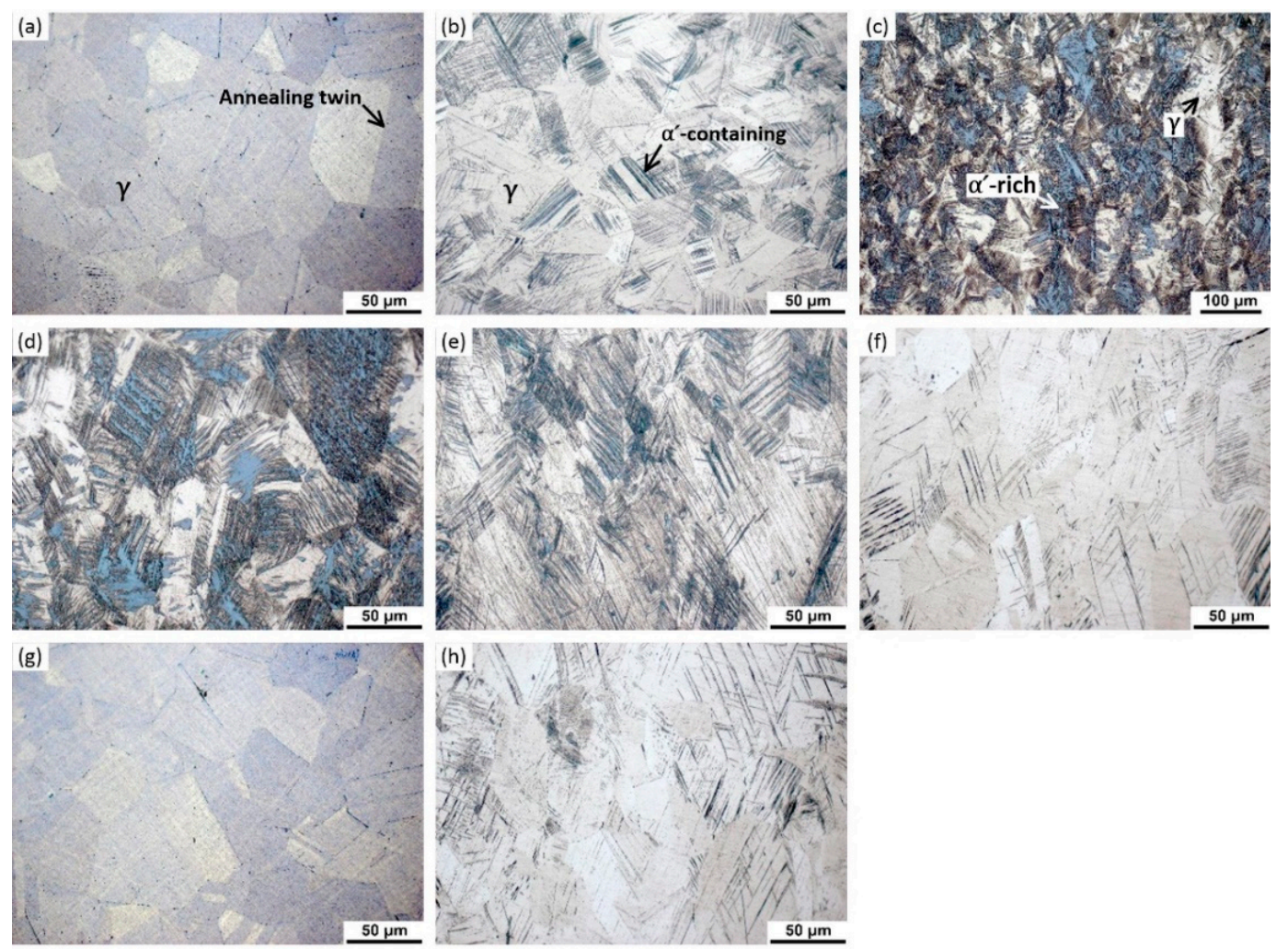

Figure 3. OM images: (a) 304L un-prestrained; (b) $304 \mathrm{~L}$ prestrained to $10 \%$ at $20{ }^{\circ} \mathrm{C}$; (c,d) $304 \mathrm{~L}$ prestrained to $30 \%$ at $20{ }^{\circ} \mathrm{C}$; (e) $304 \mathrm{~L}$ prestrained to $30 \%$ at $50{ }^{\circ} \mathrm{C}$; (f) $304 \mathrm{~L}$ prestrained to $30 \%$ at $80{ }^{\circ} \mathrm{C}$; (g) 316L un-prestrained; (h) 316L prestrained to $40 \%$ at $20^{\circ} \mathrm{C}$. The etched dark regions within the bunches of shear bands contain $\alpha^{\prime}$ martensite; the darker the region, the more the $\alpha^{\prime}$ martensite.

\subsection{Twin Boundaries and Dislocation Densities}

Boundary characteristics identified by EBSD are shown in Figure 4. Un-prestrained 304L specimen contains annealing twin boundaries, Figure $4 \mathrm{a}$. But twin boundaries in $20{ }^{\circ} \mathrm{C} 20 \%$ and $30 \%$ prestrained $304 \mathrm{~L}$ specimens appear irregular and fragmented, Figure $4 \mathrm{~b}$,c. These twin boundaries are expected to consist of both annealing and deformation twin boundaries. Typically, annealing twin boundaries after deformation appear fragmented because the concurrent deformation and grain rotation can convert a twin boundary, fully or in part, into an ordinary high angle grain boundary [40]. It is difficult to 
distinguish the two types of twin boundaries, however the fragmented twin boundaries are more likely to indicate the generation of new deformation twins [40], because the twin boundaries are more in the $30 \%$ prestrained specimen than in the $20 \%$ prestrained specimen. This also indicates that with increasing prestrain the amount of deformation twins increases. In fact, it has been established that the amount of deformation twins in 300 series ASSs increases with prestrain $[9,22,23,41]$. Shen et al. [41] found that the fraction of deformation twins in 304 steel increased with increasing strain for strain level less than $57 \%$; the volume fraction of deformation twins was about $17 \%$ at the strain level of $20 \%$. However, there are only a few twin boundary fragments in the $80{ }^{\circ} \mathrm{C}$ prestrained $304 \mathrm{~L}$ specimen, it appears that no significant deformation twin was generated by warmly prestraining.

The EBSD results confirm that there is a large fraction of BCC $\alpha^{\prime}$ platelets in $20{ }^{\circ} \mathrm{C} 30 \%$ prestrained 304L specimens. The BCC phase is 39\% vol. measured by Channel 5 HKL software, Figure $4 \mathrm{~d}$, which is slightly lower than the Feritscope reading. There are almost no $\alpha^{\prime}$ platelets in the un-prestrained and $80{ }^{\circ} \mathrm{C} 30 \%$ prestrained specimens, in line with the Feritscope readings.

On assumption that dislocation density of un-prestrained specimen is $\rho_{0}$, the relative dislocation densities $\rho / \rho_{0}$ measured by XRD are depicted in Figure 5. $\rho / \rho_{0}$ increases monotonously with prestrain, in agreement with the results of past studies [37,42]. In fact, there is a large amount of low angle boundaries in prestrained 304L specimens, Figure $4 \mathrm{~b}-\mathrm{e}$. This also indicates the generation of new dislocations. It is indicated that dislocations mainly present at the vicinity of grain boundaries and twin boundaries. Compared with $20^{\circ} \mathrm{C}$ prestrains, warm prestrains result in lower dislocation density.
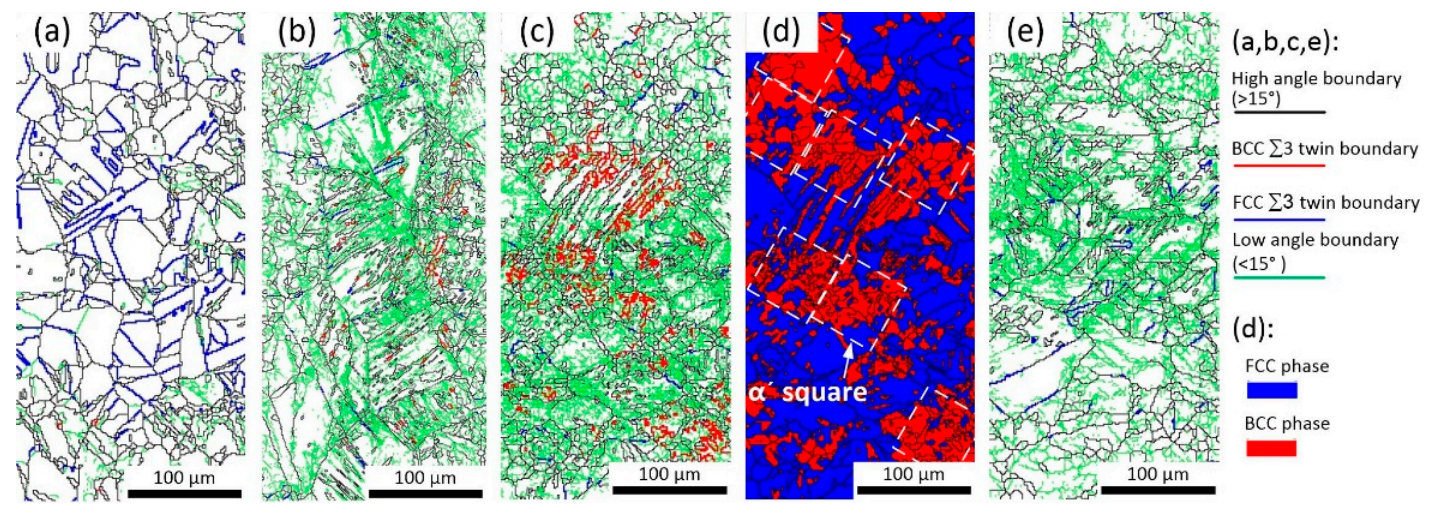

Figure 4. EBSD results of un-prestrained (a), $20{ }^{\circ} \mathrm{C} 10 \%(\mathbf{b}), 20{ }^{\circ} \mathrm{C} 30 \%(\mathbf{c}, \mathbf{d})$, and $80{ }^{\circ} \mathrm{C} 30 \%$ (e) prestrained $304 \mathrm{~L}$ steels. Blue lines in (a) are annealing twin boundaries, which become fragmented in $(\mathbf{b}, \mathbf{c})$ due to deformation (bule or red lines). (c) contains more fragmented red lines than (b) indicating the formation of deformation twins. (d) shows that $\alpha^{\prime}$ platelets can be modeled as squares.

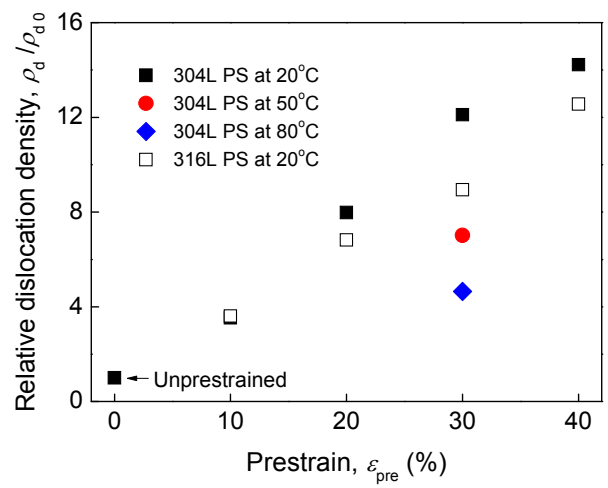

Figure 5. Relative dislocation density of un-prestrained and prestrained (PS) specimens as functions of prestrain and temperature ( $\rho_{\mathrm{d} 0}$ : the dislocation density of un-prestrained specimen). 


\subsection{Mechanical Properties}

Tensile properties are summarized in Figure $6 a, b$. The strength increases at the expense of total elongation with prestrain, indicating work-hardening due to prestraining. This has been widely-studied [43] and is related to the increases of dislocations, deformation twins, and $\alpha^{\prime}$ transformation after prestraining. After a higher level of prestrain at $20{ }^{\circ} \mathrm{C}$, since the increase in dislocations is more significant, Figure 5, and $\alpha^{\prime}$ is more, Figure 1, the work-hardening degree of steel after prestraining is more significant. However, for $304 \mathrm{~L}$ steel prestrained at higher temperatures and 316L steel prestrained at $20{ }^{\circ} \mathrm{C}$, since the increase of dislocations and/or $\alpha^{\prime}$ transformation is less significant, the work-hardening after prestraining is less significant. Hydrogen-charging has almost no influence on the yield strength of two steels but reduces the tensile strength and total elongation, indicating $\mathrm{HE}$.
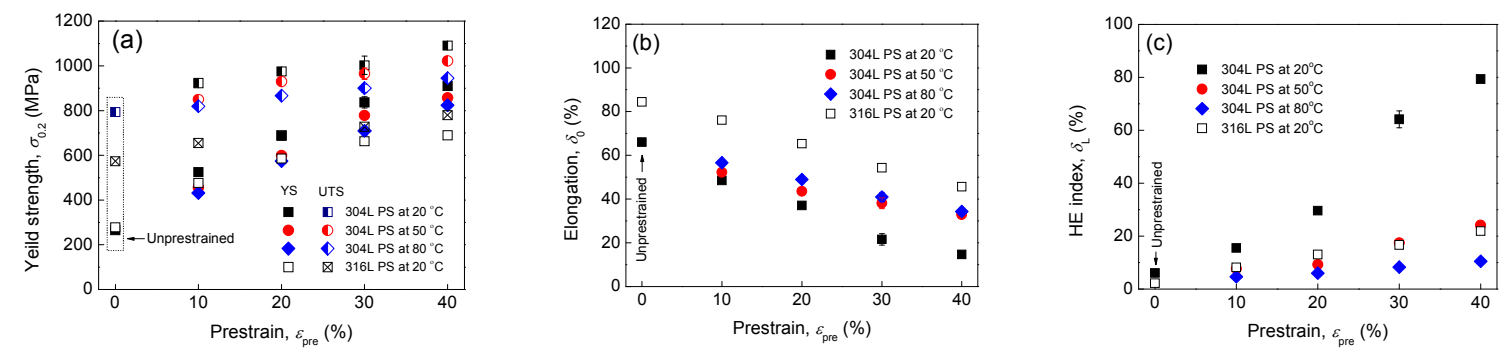

Figure 6. Yield strength (a), total elongation (b), and HE index (c) of un-prestrained and prestrained (PS) specimens as functions of prestrain level and temperature.

\subsection{HE Susceptibility Index}

The HE indexes calculated by Equation (3) are summarized in Figure 6c. Un-prestrained 304L and 316L specimens have a HE index of $6 \%$ and $2 \%$, respectively, confirming that solution-annealed two steels possess good HE resistance. In addition, 316L steel is less sensitive to hydrogen. Nevertheless, prestrains at $20{ }^{\circ} \mathrm{C}$ enhance the $\mathrm{HE}$ of $304 \mathrm{~L}$ steel, particularly the prestrains higher than $20 \%$. At $10 \%$ prestrain, the HE index of $304 \mathrm{~L}$ steel is $15 \%$, but at $30 \%$ prestrain it is $64 \%$, at $40 \%$ prestrain it is 79\%, indicating very severe HE. However, turning to 316L steel, the HE index is increased from $2 \%$ for un-prestrained specimen to $8 \%$ by $10 \%$ prestrain, to $17 \%$ by $30 \%$ prestrain, and to $22 \%$ by $40 \%$ prestrain, thus the enhancement of HE due to prestraining for 316L steel is not as significant as 304L steel. After prestraining, 316L steel still has a relatively higher HE resistance. Increasing prestrain temperature, Figure $6 \mathrm{c}$ shows that, the HE degree of 304L steel decreases, as compared with those prestrained at $20{ }^{\circ} \mathrm{C}$. At $50{ }^{\circ} \mathrm{C}$, even if the prestrain level is $40 \%$, the $\mathrm{HE}$ degree is just slightly higher than un-prestrained specimen. Further elevating the prestrain temperature to $80{ }^{\circ} \mathrm{C}$, the $\mathrm{HE}$ degrees at various prestrain levels are very close to that of un-prestrained specimen. Also, after high temperature prestrains, the HE degree of 304L steel becomes less dependent on prestrain, similar with 316L steel prestrained at $20^{\circ} \mathrm{C}$. It seems that warm prestrains have a little influence on $\mathrm{HE}$ of $304 \mathrm{~L}$ steel.

\subsection{Fracture Surface Morphologies}

All specimens without charging exhibit evident necking and show dimples in the whole fracture surfaces, revealing a ductile fracture. But all charged specimens exhibit smaller reduction of area (RA) and two regions with different fracture features. The central regions show dimples, but the edge regions show brittle fracture mode. Representative fracture surfaces are shown in Figures 7-9.

Brittle region of un-prestrained 304L specimen exhibits quasi-cleavage (QC) fracture with some flat facets (FFs) and secondary cracks (SCs), Figure 7b, which is typical fracture characteristic of $\mathrm{HE}$ in metastable 300 series ASSs [2,4,7-9,19-21]. As mentioned, FFs can be related to hydrogen-assisted twin boundary cracking [19-21]. Nevertheless, besides QC fracture, FFs and SCs, $20{ }^{\circ} \mathrm{C}$ prestrained 
304L steel also show intergranular (IG) fracture, Figure 7d,f and Figure $9 \mathrm{~b}$ indicate more severe HE. The depth of brittle region, number of FFs, and proportion of IG fracture increase with prestrain, indicating that HE increases with prestrain, in line with the trend of HE index calculated by Equation (3). The results imply that a higher prestrain can modify the HE mechanism of metastable 304L steel.
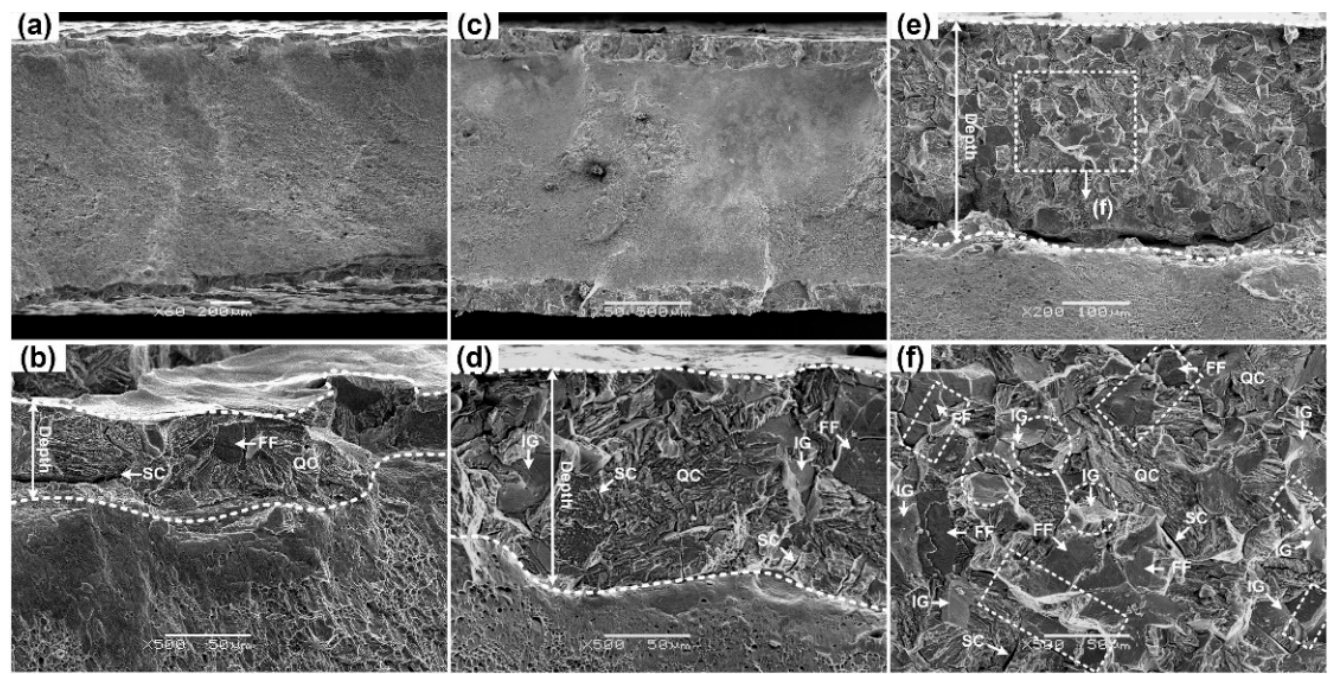

Figure 7. SEM fracture surfaces of the 304L steel specimens: (a,b) Un-prestrained; (c,d) prestrained to $20 \%$ at $20{ }^{\circ} \mathrm{C} ;(\mathbf{e}, \mathbf{f})$ prestrained to $40 \%$ at $20{ }^{\circ} \mathrm{C}$.

The edge region of un-prestrained 316L steel exhibits also QC, whereas compared to 304L steel the depth of brittle region is smaller and SCs are tinier, Figure $8 b$, confirming higher HE resistance of $316 \mathrm{~L}$ steel. Unlike $304 \mathrm{~L}$ steel prestrained at $20{ }^{\circ} \mathrm{C}$, there is no much difference in fracture surface characteristic between un-prestrained and prestrained 316L specimens, Figure 8d. On the other hand, all fracture surfaces of high-temperature prestrained 304L specimens show QC fracture with FFs and SCs but without IG fracture, Figure 9d,f. Thus, the results indicate that, for 316L steel prestrained at $20^{\circ} \mathrm{C}$ and 304L steel prestrained at higher temperatures, in which little or no $\alpha^{\prime}$ was detected after prestraining, prestrains up to $40 \%$ have little influence on the HE mechanism. This is different from the case of $304 \mathrm{~L}$ steel prestrained at $20^{\circ} \mathrm{C}$, in which an amount of $\alpha^{\prime}$ was detected after prestraining.
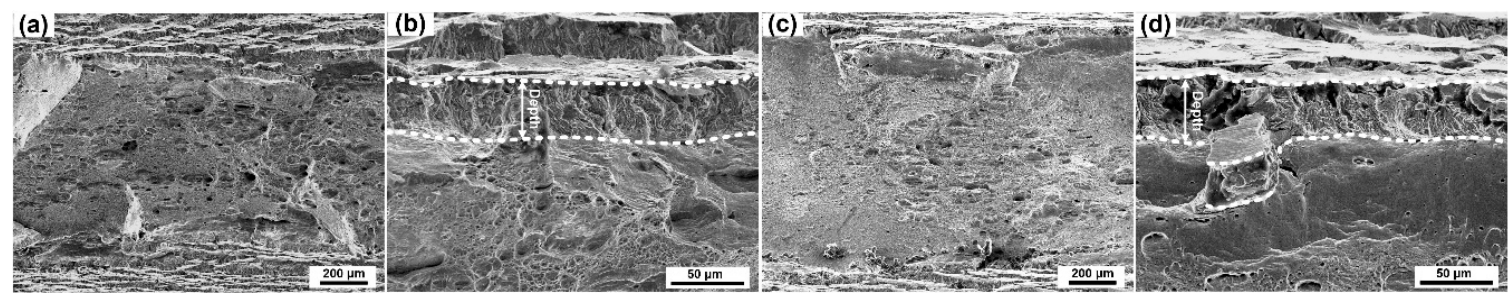

Figure 8. SEM surfaces of 316L specimens: $(\mathbf{a}, \mathbf{b})$ Un-prestrained; $(\mathbf{c}, \mathbf{d})$ prestrained to $30 \%$ at $20{ }^{\circ} \mathrm{C}$. 

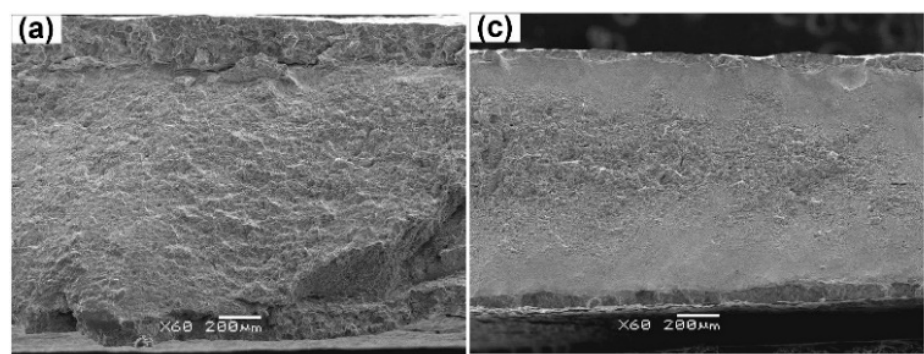

(e)
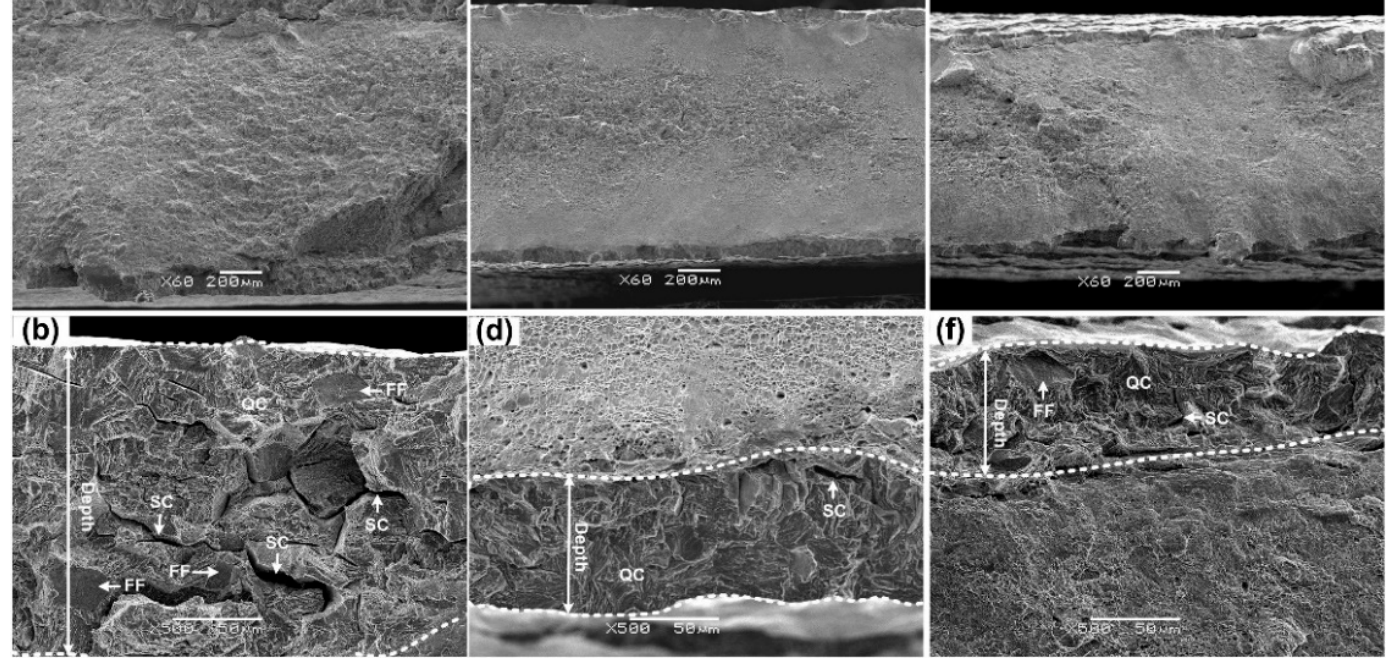

Figure 9. SEM surfaces of $304 \mathrm{~L}$ specimens. (a,b) Prestrained to $30 \%$ at $20{ }^{\circ} \mathrm{C} ;(\mathbf{c}, \mathbf{d})$ prestrained to $30 \%$ at $50{ }^{\circ} \mathrm{C} ;(\mathbf{e}, \mathbf{f})$ prestrained to $30 \%$ at $80{ }^{\circ} \mathrm{C}$.

\subsection{Hydrogen Diffusivity and Solubility}

Figures 7-9 show that the depth of brittle region, denoted as $x_{\max }$, varies with specimen condition. $304 \mathrm{~L}$ specimens heavily prestrained at $20^{\circ} \mathrm{C}$ exhibit larger $x_{\max }$ and smaller RA, thus more severe $\mathrm{HE}$, whereas $304 \mathrm{~L}$ prestrained at 50 and $80{ }^{\circ} \mathrm{C}$ and $316 \mathrm{~L}$ specimens prestrained at $20^{\circ} \mathrm{C}$ exhibit smaller $x_{\max }$ and larger RA, thus milder HE. The HE of specimen increases with $x_{\max }$.

The depth of brittle region can represent the distance of hydrogen transporting into the interior of specimen at end of charging, thus many researchers have used it to approximately calculate the apparent hydrogen diffusivity based on Fick's law. For thick plate specimens, the distribution of hydrogen along the depth direction during charging can be formalized by [44]

$$
c(x, t)=c_{\mathrm{i}}+\left(c_{\mathrm{s}}-c_{\mathrm{i}}\right)\left[1-\operatorname{erf}\left(\frac{x}{2 \sqrt{D_{a p p t}}}\right)\right]
$$

where $x$ is depth from surface; $c_{\mathrm{i}}$ is initial hydrogen concentration in specimen; $c_{\mathrm{S}}$ is hydrogen concentration dissolved at specimen surface during charging, which is apparent hydrogen solubility; $D_{\text {app }}$ is apparent diffusivity of hydrogen; $t$ is charging time. Since when $x / 2 \sqrt{D_{\text {app }} t} \geq 2, c$ approaches to 0 , hence, the hydrogen transport depth (taking it equal to $x_{\max }$ as an approximation) at end of hydrogen-charging can be calculated by taking $x / 2 \sqrt{D_{\text {app }} t}=2[45,46]$, thus we have

$$
D_{\text {app }}=\frac{x_{m a x}^{2}}{16 t}
$$

Based on Equation (5), $D_{\text {app }}$ was calculated, Figure 10a. $D_{\text {app }}$ of un-prestrained 304L and 316L steels are $7.6 \times 10^{-16}$ and $5.5 \times 10^{-16} \mathrm{~m}^{2} / \mathrm{s}$, respectively, in good agreement with data reported [44,47] $\left(1.8 \sim 8 \times 10^{-16} \mathrm{~m}^{2} / \mathrm{s}\right)$ for solution-annealed ASSs. Thus, $D_{\text {app }}$ calculated by Equation (5) is acceptable. Figure 10a shows that $D_{\text {app }}$ in $304 \mathrm{~L}$ steel is significantly increased by prestrain at $20^{\circ} \mathrm{C}$. The higher the prestrain applied the higher the $D_{\text {app }} . D_{\text {app }}$ are $1.7 \times 10^{-14}$ and $3.9 \times 10^{-14} \mathrm{~m}^{2} / \mathrm{s}$, respectively, in 30 and $40 \%$ prestrained specimens, being about 22 and 51 times higher than that of the un-prestrained 304L specimen. However, $D_{\text {app }}$ of $304 \mathrm{~L}$ specimens prestrained to $30 \%$ and $40 \%$ at $50{ }^{\circ} \mathrm{C}$ are just slightly higher than that of un-prestrained specimen, and $D_{\text {app }}$ of specimens prestrained to $30 \%$ and $40 \%$ at $80^{\circ} \mathrm{C}$ are very close to that of un-prestrained specimens. $D_{\text {app }}$ of $304 \mathrm{~L}$ specimens with a lower level of prestrain at higher temperatures, i.e., $10 \%$ at $50{ }^{\circ} \mathrm{C}$ and $10 \%$ and $20 \%$ at $80{ }^{\circ} \mathrm{C}$, are even slightly 
lower than that of un-prestrained specimen. These results indicate that prestrains at 50 and $80{ }^{\circ} \mathrm{C}$, particularly at $80^{\circ} \mathrm{C}$, have a relatively lesser influence on $D_{\text {app }}$ of $304 \mathrm{~L}$ steel, compared with prestrains at $20^{\circ} \mathrm{C}$. In addition, prestrains at $20^{\circ} \mathrm{C}$ also have a lesser influence on $D_{\text {app }}$ of 316L steel.

Total hydrogen mass, $m_{\mathrm{H}}$, obtained by ONH836 analyzer are shown in Figure $10 \mathrm{~b} . m_{\mathrm{H}}$ increased with prestrain for $304 \mathrm{~L}$ steel prestrained at $20{ }^{\circ} \mathrm{C}$. However, there is no evident difference between un-prestrained and $20{ }^{\circ} \mathrm{C} 30 \%$ prestrained 316L steel. At 30\% prestrain, the higher the temperature used, the less the $m_{\mathrm{H}}$ was charged into $304 \mathrm{~L}$ steel. $m_{\mathrm{H}}$ of $80{ }^{\circ} \mathrm{C} 30 \%$ pretrained specimen is just slightly higher that of the un-prestrained specimen. $m_{\mathrm{H}}$ can be approximately calculated by

$$
m_{\mathrm{H}}=\rho L P e \int_{0}^{x_{\max }} c(x, t) \mathrm{d} x
$$

where, $L$ and $P e$ are length and perimeter of specimen at gauge cross-section, respectively, and $\rho$ is density. Inserting $D_{\mathrm{app}}$ and $m_{\mathrm{H}}$ values into Equations (5) and (6), solubility $c_{\mathrm{s}}$ was calculated, Figure 10c. The results indicate that $c_{\mathrm{s}}$ in $304 \mathrm{~L}$ steel decreases with increasing prestrain at $20{ }^{\circ} \mathrm{C}$, particularly for prestrain higher than $20 \%$, whereas $c_{\text {s }}$ of $316 \mathrm{~L}$ steel prestrained at $20{ }^{\circ} \mathrm{C}$ and of $304 \mathrm{~L}$ steel prestrained at higher temperatures are slightly higher than their un-prestrained specimens. The results indicate that a high level of prestrain at $20^{\circ} \mathrm{C}$ can decrease significantly the apparent solubility of 304L steel, whereas a prestrain at higher temperatures has relatively little influence on the solubility. A prestrain even at $20{ }^{\circ} \mathrm{C}$ has little influence on the apparent solubility of 316L steel.
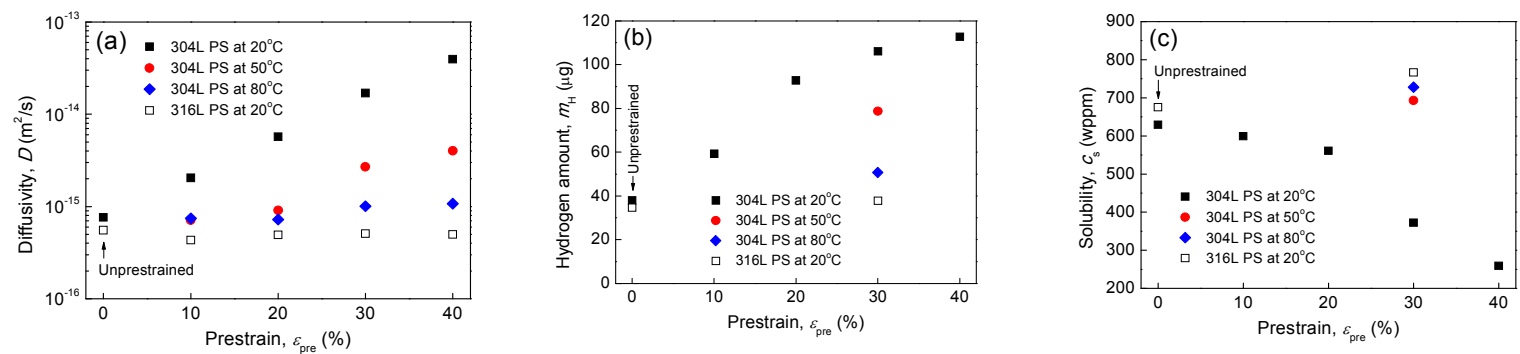

Figure 10. Apparent hydrogen diffusivity (a), total hydrogen amount (b), and apparent solubility (c) of un-prestrained and prestrained (PS) specimens as functions of prestrain level and temperature.

\section{Discussion}

\subsection{Role of Pre-Existing $\alpha^{\prime}$ Martensite}

Many studies [1-4,9-11] have regarded $\alpha^{\prime}$ induced by prior deformation as the key contributor to enhanced HE of 300 series ASSs. Clearly, the significant increase in HE of 304L steel after a higher prestrain at $20{ }^{\circ} \mathrm{C}$ can also be attributed to $\alpha^{\prime}$. Figure 11a depicts HE indexes of all specimens as a function of $\alpha^{\prime}$ fraction. Regardless of prestrain and temperature, HE index is directly proportional to $\alpha^{\prime}$ content. The studies [1-4,9-11] believed that the role of pre-existing $\alpha^{\prime}$ is to provide diffusion "highways" during hydrogen exposure. To verify this, Figure $11 b, c$ display $D_{\text {app }}$ and $m_{\mathrm{H}}$ values, respectively, as a function of $\alpha^{\prime}$. Both $D_{\text {app }}$ and $m_{\mathrm{H}}$ increases with $\alpha^{\prime}$ fraction. Thus, it is undeniable that pre-existing $\alpha^{\prime}$ can act as diffusion "highways", enhancing transport rate and hydrogen uptake during hydrogen exposure. With increasing prestrain, since the content of $\alpha^{\prime}$ increases, the hydrogen transport rate and total hydrogen amount entering is increased, the HE of metastable 304L steel is more severe. On the contrary, since the $\alpha^{\prime}$ is less significant in the prestrained 316L steel and the warmly prestrained $304 \mathrm{~L}$ steel, their $D_{\text {app }}$ are less affected and their HE is less severe.

Figure 11d depicts the apparent solubility calculated by Equation (6), although total hydrogen amount into a specimen increases with increasing $\alpha^{\prime}$ fraction, the $c_{\mathrm{S}}$ decreases rapidly with $\alpha^{\prime}$. This is because the solubility of hydrogen is much lower in $\alpha^{\prime}$ than in $\gamma$. This also indicates that the hydrogen charged into was mainly stored inside $\gamma$ phase. Evidently, there is a competition between the reduction 
of solubility (hydrogen concentration dissolved at surface) and the increase of apparent diffusivity due to $\alpha^{\prime}$. In fact, Figure 11c shows that $m_{\mathrm{H}}$ initially rapidly increases with increasing prestrain, but later becomes not much changed with further increasing prestrain, because of the competition.

\subsection{Role of Initial Dislocation Density}

It is believed that IHE and HEE are the same on an atomic scale, but macroscopically there are significant differences between them. Discussions on the differences can be referred to a previous work [48]. The most important difference is that the transport processes of hydrogen in IHE and HEE are different. On one hand, HEE is more complicated because several steps (including gaseous hydrogen transport, physical adsorption, dissociation of molecules, chemisorption, and diffusion in metals) are required to transport hydrogen from environment into metal lattice. On the other hand, strong interactions exist between hydrogen transport and plastic deformation (dislocation glides). It is believed that hydrogen transport by moving dislocations [49] is the most important transport mechanism in HEE.

Michler et al. [14] suggested that the increase of dislocations after deforming is more crucial than $\alpha^{\prime}$ in HEE of cold-worked ASSs. In annealed ASSs, the dislocation population is low, thus dissolved hydrogen amount is low. But after deforming, since dislocations increases, the hydrogen amount that dissolved and can be transported by moving dislocations increases [14], leading to enhanced HE. However, turning to the IHE of 304L steel prestrained, it appears that the contribution of dislocation density is minor, compared with pre-existing $\alpha^{\prime}$, based on two aspects.

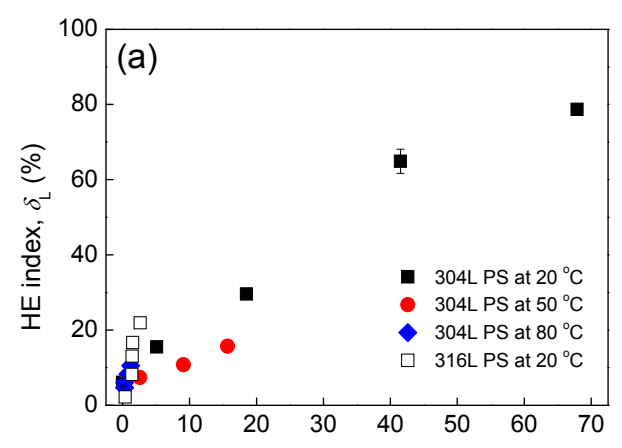

Volume fraction of $\alpha^{\prime}$ martensite, $f_{\alpha^{\prime}}(\%)$

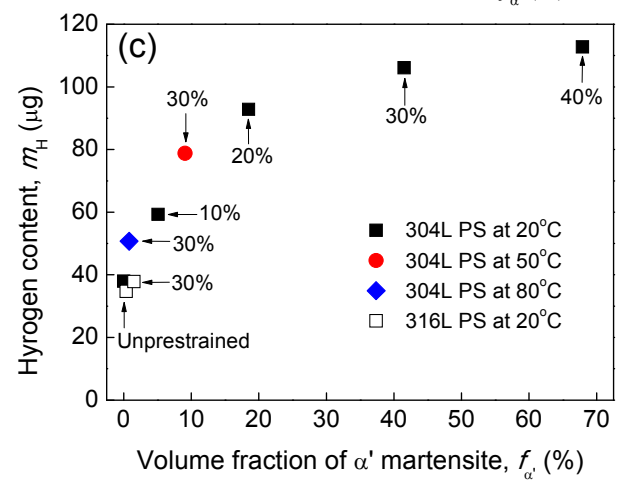

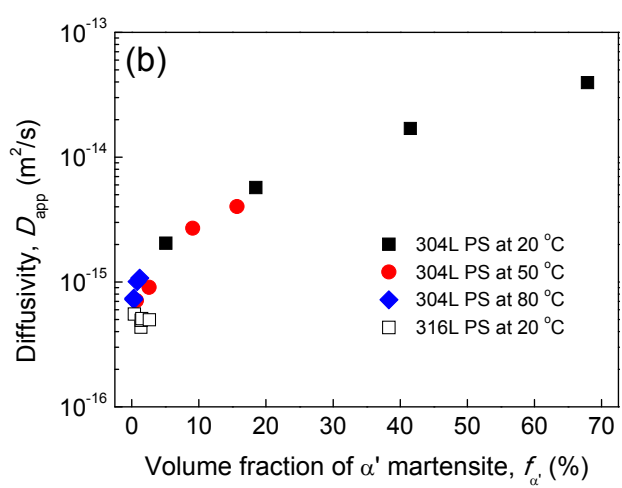

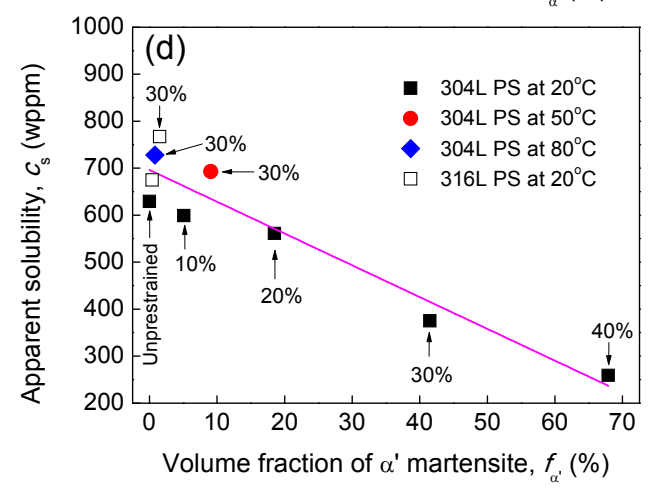

Figure 11. HE indexes (a), apparent hydrogen diffusivity (b), total hydrogen amount (c), and apparent solubility (d) of specimens un-prestrained and prestrained (PS) as a function of $\alpha^{\prime}$ volume fraction.

- Compared with pre-existing $\alpha^{\prime}$, the effect of initial dislocation density on apparent parameters is minor.

As mentioned, dislocations acting as trap sites can decrease the apparent hydrogen diffusivity but increase solubility of BCC carbon and low alloy steels. However, Figure 11c shows contrary results for FCC 304L steel. Thus, the increasing (decreasing) effect of dislocation multiplication on the apparent 
solubility (diffusivity) is negligible compared to the decreasing (increasing) effect of $\alpha^{\prime}$ on solubility (diffusivity). In addition, Figure 11c shows that, for high-temperature prestrained 304L specimens and $20^{\circ} \mathrm{C}$ prestrained 316L specimens, although their dislocation density increased after prestrain, their apparent diffusivity remains almost unchanged and solubility are just slightly higher than that of un-prestrained specimen, confirming again that the effect of dislocation increase on apparent solubility and diffusivity is minor. In fact, as mentioned, Perng and Altstetter [1] and Mine et al. [2] have also found that even after a very high level of deformation (for example, up to $80 \%$ deformation for 310 steel) apparent diffusivity is less affected. In the IHE condition, since a large amount of hydrogen has already been transported into the steel by $\alpha^{\prime}$ "highways" before loading, hydrogen can readily interact with deformation and/or reduce cohesive energy during loading. Hydrogen transport by moving dislocations is not the essential step in such case.

- Compared with pre-existing $\alpha^{\prime}$, the effect of initial dislocation density on HE degree is minor.

In more stable $316 \mathrm{~L}$ steel after prestraining at $20^{\circ} \mathrm{C}$ and $304 \mathrm{~L}$ steel after prestraining at higher temperatures, dislocation densities are also significantly increased, Figure 5. However, their HE degrees are just slightly increased, Figure $6 \mathrm{c}$. Thus, the prestrain-induced increase in dislocation density has relatively little influence on the HE of ASSs. On the contrary, for $304 \mathrm{~L}$ specimens prestrained at $20{ }^{\circ} \mathrm{C}$, a large fraction of $\alpha^{\prime}$ was induced by prestraining, consequently their HE was markedly enhanced.

\subsection{Role of Twin Boundaries}

As revealed, high levels of prestrain modify the HE mechanism of 304L steel by showing more FFs and IG fractures. Moreover, Figure $7 \mathrm{~d}$, f shows that IG fracture initiated mainly at grain boundaries impinging on twins and grain boundary triple junctions. Many SCs "wedged" into grain-twin boundaries and some FFs intersected. These features are rarely observed in solution-annealed and hydrogenated ASSs but have been observed in TWIP steels [16-18]. Thus, the presence of these fracture features can be attributed to deformation twins after prestraining and can be explained schematically by Figure 12 from the following two aspects.

(1) Stress concentration. Moving dislocations and progressing twins can be intercepted by grain or twin boundaries, leading to stress concentration [16-18], Figure 12a. In addition, $\alpha^{\prime}$ platelets, which form preferably at deformation twins, intersections between twins, and at twin or grain boundary intersections, can also lead to stress concentration [16-18]. In fact, Figure 3 has shown that $\alpha^{\prime}$ platelets mainly formed within the bunches of shear bands, where deformation twins also present [41].

(2) Hydrogen accumulation. Clearly, stress concentration at grain or twin boundaries can induce hydrogen accumulation due to stress-assisted hydrogen diffusion [44], Figure 12b(2). Moreover, since dislocations are trapping sites for diffusible hydrogen (grain boundaries are also trap sites), hydrogen can be transported to grain or twin boundaries by moving dislocations [49], Figure 12b(1). Figure 4 has indicated that more dislocations present at the vicinity of grain boundaries and twin boundaries. Furthermore, hydrogen can also be transported to these boundaries and their intersections through $\alpha^{\prime}$ "highways" for hydrogen diffusion, Figure 12b(3). Thus, hydrogen can accumulate on grain or twin boundaries and their intersections. Under the combined action of stress concentration and concentrated diffusible hydrogen, IG fracture initiates at the intersections of grain-grain/grain-twin boundaries and crack propagation occurs along grain or twin boundaries, because the cohesive energy of these intersections and boundaries is reduced by hydrogen, Figure 12c. 

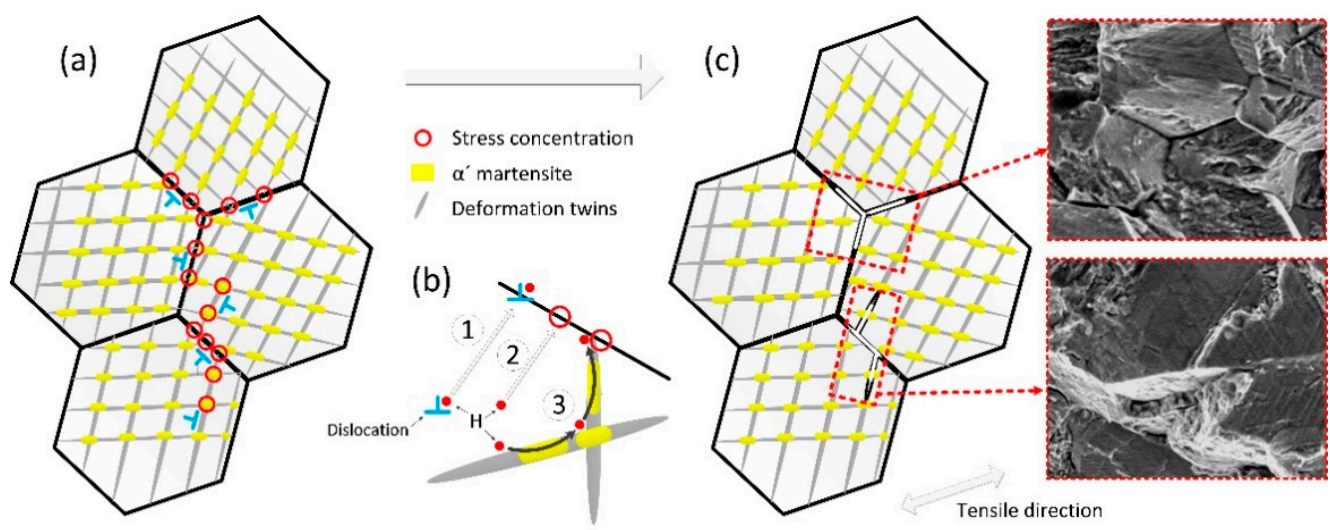

1. $\mathrm{H}$ transport by moving dislocations; $2 \mathrm{H}$ transport driven by stress gradient; $3 \mathrm{H}$ transport along martensite highways.

Figure 12. Schematics for the intergranular (IG) cracking and twin boundary separations. (a) Stress concentrations arising at the grain or twin boundaries and their intersections; (b) Hydrogen transport ways to these boundaries and intersections: (1) transported by moving dislocations, (2) stress-assisted hydrogen diffusion, (3) transported through $\alpha^{\prime}$ "highways"; (c) IG fracture initiates at the intersections.

\subsection{Warm Prestrain: Strengthening ASSs without Impairing Their HE Resistance}

To widen the applications of ASSs, cold-deformations have been often applied to ASS parts or their surface layers to strengthen/harden them. However, if $\alpha^{\prime}$ transformation occurs during cold-deformation, the HE resistance and hydrogen permeation resistance can be reduced. The results of this study imply that, for ASSs that will be deformed, elevating the deformation temperature is an applicable method to suppress $\alpha^{\prime}$ transformation, consequently preserving their HE resistance. For $304 \mathrm{~L}$ steel investigated, which has a $\mathrm{Md}_{30}$ temperature close to room temperature, 50 and $80^{\circ} \mathrm{C}$ prestrains are easy to operate. More importantly, the results show that, although high-temperature prestrains do not strengthen the $304 \mathrm{~L}$ steel as effective as $20^{\circ} \mathrm{C}$ prestrain due to less significant $\alpha^{\prime}$ transformation, they still elevate the strength of $304 \mathrm{~L}$ steel by a large degree. For example, $30 \%$ prestrain at $20{ }^{\circ} \mathrm{C}$ elevates the yield strength from 263 to $847 \mathrm{MPa}$ by 3.2 times, whereas $30 \%$ prestrain at $50{ }^{\circ} \mathrm{C}$ elevates it to $785 \mathrm{MPa}$ by 3.0 times, $30 \%$ prestrain at $80^{\circ} \mathrm{C}$ elevates it to $720 \mathrm{MPa}$ by 2.7 times. Moreover, since $\alpha^{\prime}$ transformation is less significant at higher temperatures, 304L steel still has a relatively higher plasticity. For example, the total elongation of un-prestrained $304 \mathrm{~L}$ specimen is $66 \%$, after $40 \%$ prestrain at $20{ }^{\circ} \mathrm{C}$ it reduces to only $14 \%$, whereas it is $27 \%$ after $40 \%$ prestrain at $50{ }^{\circ} \mathrm{C}, 33 \%$ after $40 \%$ prestrain at $80^{\circ} \mathrm{C}$. Such level of plasticity is attractive to the components exposing to hydrogen compared with carbon and low alloy steels having a similar strength level.

\section{Hydrogen Transport in Duplex Materials}

The ASSs after a higher level of plastic deformation consist of both FCC $\gamma$ and BCC $\alpha^{\prime}$, thus they can be considered as duplex materials. The more typical duplex materials include the duplex stainless steels containing BCC ferrite and austenite (e.g., 2205) and the martensitic stainless steel containing retained austenite (e.g., 13\% Cr). Hydrogen transport is more complicated in FCC + BCC duplex materials, because the dispersed austenite platelets possess low hydrogen diffusivity but high solubility and the transport path of hydrogen is tortuous. To understand the HE mechanisms/kinetics of duplex materials and to control/predict their HE, the knowledge of transport properties and hydrogen distribution of duplex materials is essential. Thus, over the years, many researchers have made efforts to study the hydrogen transport of duplex materials. In this section, we discuss the hydrogen transport of duplex materials by means of both theoretical analysis and FE simulations. 


\subsection{Theoretical Analysis}

By viewing the platelets of two phases as organized in a parallel or series geometrical configuration, Gesnouin et al. [50] have proposed two extreme cases to describe the hydrogen permeation rate $\Phi_{\text {app }}$ of a duplex material, i.e., parallel configuration:

$$
\Phi_{\mathrm{app}}=\Phi_{\mathrm{bcc}} f_{\mathrm{bcc}}+\Phi_{\mathrm{fcc}} f_{\mathrm{fcc}}
$$

and series configuration:

$$
\frac{1}{\Phi_{\mathrm{app}}}=\frac{f_{\mathrm{bcc}}}{\Phi_{\mathrm{bcc}}}+\frac{f_{\mathrm{fcc}}}{\Phi_{\mathrm{fcc}}}
$$

where $\Phi_{\mathrm{bcc}}$ and $\Phi_{\mathrm{fcc}}$ are permeation rates, $f_{\mathrm{bcc}}$ and $f_{\mathrm{fcc}}$ are fractions of BCC and FCC phase, respectively, $f_{\mathrm{fcc}}=1-f_{\mathrm{bcc}}$. The permeation rate $\Phi$ is the product of solubility constant $s$ and diffusivity $D$, i.e., $\Phi=S D$. Regardless of geometrical configuration, the apparent hydrogen solubility $c_{\text {sapp }}$ can be described as

$$
c_{\mathrm{sapp}}=c_{\mathrm{sbcc}} f_{\mathrm{bcc}}+c_{\mathrm{sfcc}} f_{\mathrm{fcc}}
$$

where $c_{\text {sbcc }}$ and $c_{\text {sfcc }}$ are solubilities of BCC and FCC phase. Thus, Equations (7) and (8) are rewritten as

$$
\begin{gathered}
D_{\mathrm{app}}\left(c_{\mathrm{sbcc}} f_{\mathrm{bcc}}+c_{\mathrm{sfcc}} f_{\mathrm{fcc}}\right)=D_{\mathrm{bcc}} c_{\mathrm{sbcc}} f_{\mathrm{bcc}}+D_{\mathrm{fcc}} c_{\mathrm{sfcc}} f_{\mathrm{fcc}} \\
\frac{1}{D_{\mathrm{app}}\left(c_{\mathrm{sbcc}} f_{\mathrm{bcc}}+c_{\mathrm{sfcc}} f_{\mathrm{fcc}}\right)}=\frac{f_{\mathrm{fcc}}}{D_{\mathrm{fcc}} c_{\mathrm{sfcc}}}+\frac{f_{\mathrm{bcc}}}{D_{\mathrm{bcc}} c_{\mathrm{sbcc}}}
\end{gathered}
$$

where $D_{\mathrm{bcc}}$ and $D_{\mathrm{fcc}}$ are diffusivities of BCC and FCC phase, respectively. Table 2 gives a summary of hydrogen transport parameters reported for BCC and FCC phase $[1,44,47,51,52]$. Since $D_{\text {bcc }}$ is 5-6 orders of magnitude higher than $D_{\mathrm{fcc}}$, but $c_{\mathrm{sbcc}}$ is 2-3 orders of magnitude lower than $c_{\mathrm{sfc}}$, we can expect that $D_{\mathrm{bcc}} \mathcal{c}_{\mathrm{sbcc}} f_{\mathrm{bcc}} \gg D_{\mathrm{fcc}} \mathcal{c}_{\mathrm{sfcc}} f_{\mathrm{fcc}}$ for a duplex material, in which BCC phase is rich. Thus, for the parallel configuration, the last items of Equation (10) is ignored, Equation (10) becomes

$$
D_{\text {app }}=\frac{D_{\text {bcc }}}{1+\left(c_{\text {sfcc }} f_{\mathrm{fcc}}\right) /\left(c_{\mathrm{sbcc}} f_{\mathrm{bcc}}\right)}
$$

Since $c_{\mathrm{sfcc}}>>c_{\mathrm{sbcc}},\left(c_{\mathrm{sfcc}} f_{\mathrm{fcc}}\right) /\left(c_{\mathrm{sbcc}} f_{\mathrm{bcc}}\right)>>1$. Equation (12) becomes

$$
\log D_{\mathrm{app}}=\log \frac{D_{\mathrm{bcc}} c_{\mathrm{sbcc}}}{c_{\mathrm{sfcc}}}+\log \frac{f_{\mathrm{bcc}}}{1-f_{\mathrm{bcc}}}
$$

Equation (13) indicates a simple linear relation between $\log D_{\text {app }}$ and $\log \left[f_{\mathrm{bcc}} /\left(1-f_{\mathrm{bcc}}\right)\right]$. Since $c_{\mathrm{sfcc}}>>c_{\mathrm{sbcc}}$, Equation (9) can be simplified as

$$
c_{\mathrm{sapp}}=c_{\mathrm{sfcc}}\left(1-f_{\mathrm{bcc}}\right)
$$

indicating that there is also a simple linear relation between $c_{\text {sapp }}$ and $f_{\mathrm{bcc}}$ for a duplex material.

$\gamma$ platelets are also believed to play roles as hydrogen trap sites. According to Oriani's theory [53], if the local equilibrium of hydrogen is maintained between lattice sites and trap sites, the apparent diffusivity of hydrogen can be given by

$$
D_{\text {app }}=\frac{D_{\mathrm{L}}}{1+N_{\mathrm{t}} / N_{\mathrm{L}} \exp \left(-E_{\mathrm{B}} / R T\right)}
$$

where $D_{\mathrm{L}}$ is lattice diffusivity, $N_{\mathrm{L}}$ is number of lattice sites, $N_{\mathrm{t}}$ is number of trapping sites, and $E_{\mathrm{B}}$ is binding energy of hydrogen to trap sites. Considering $\gamma$ platelets are trap sites, $D_{\mathrm{L}}, N_{\mathrm{t}}, N_{\mathrm{L}}$, and $E_{\mathrm{B}}$ should be replaced by $D_{\mathrm{bcc}}\left(1-f_{\mathrm{bcc}}\right), f_{\mathrm{bcc}}$ and $\left(E_{\mathrm{Bfcc}}-E_{\mathrm{Bbcc}}\right)$, respectively, where $E_{\mathrm{Bfcc}}$ and $E_{\mathrm{Bbcc}}$ are 
binding energy of hydrogen to dislocations in FCC and BCC phase, respectively. Moreover, at lower temperatures, the 2 nd term in the denominator is predominant. Thus, Equation (15) becomes

$$
\log D_{\mathrm{app}}=\log \frac{D_{\mathrm{bcc}}}{\exp \left[-\left(E_{\mathrm{Bfcc}}-E_{\mathrm{Bbcc}}\right) / R T\right]}+\log \frac{f_{\mathrm{bcc}}}{1-f_{\mathrm{bcc}}}
$$

Table 2. Hydrogen transport parameters used for the theoretical modeling and FE simulations.

\begin{tabular}{|c|c|c|c|c|}
\hline \multirow{2}{*}{ Parameter } & \multirow{2}{*}{ Values Reported in Literatures } & \multicolumn{3}{|c|}{ Values Used } \\
\hline & & $20-50^{\circ} \mathrm{C}$ & $70-110^{\circ} \mathrm{C}$ & $\sim 200^{\circ} \mathrm{C}$ \\
\hline $\begin{array}{c}D_{\mathrm{bcc}} \\
\left(\times 10^{-11} \mathrm{~m}^{2} / \mathrm{s}\right)\end{array}$ & $\begin{array}{c}\sim 25^{\circ} \mathrm{C}: 1.5[51] ; 6.0[52] ; 0.6[47] . \\
6.40 \times 10^{-5} \exp \left(\frac{-7.0(\mathrm{~kJ} / \mathrm{mol})}{R T}\right)\left(25^{\circ} \mathrm{C}: 1\right)[1]^{1}\end{array}$ & 1.0 & 8 & 80 \\
\hline $\begin{array}{c}D_{\mathrm{fcc}} \\
\left(\times 10^{-16} \mathrm{~m}^{2} / \mathrm{s}\right)\end{array}$ & $\begin{array}{c}\sim 25^{\circ} \mathrm{C}:(1.8 \sim 8)[44] ; 3.3 \text { [47]; } 1.4[52] ; \sim 7.0^{2} \\
110{ }^{\circ} \mathrm{C}: 300[2] .\end{array}$ & 6.0 & 100 & 10,000 \\
\hline$\left(\times 10^{-3} \mathrm{ppm} / \sqrt{\mathrm{Pa}}\right)$ & $\begin{array}{c}1.6 \times 10^{-2} \exp \frac{-4.7(\mathrm{~kJ} / \mathrm{mol})}{R T}\left(T<170^{\circ} \mathrm{C}\right) \\
2.1 \times 10^{1} \exp \frac{-31.4(\mathrm{~kJ} / \mathrm{mol})}{R T}\left(T>170^{\circ} \mathrm{C}\right)[1]^{1}\end{array}$ & 1.0 & 3.0 & 7.0 \\
\hline $\begin{array}{c}s_{\mathrm{fcc}} \\
(\mathrm{ppm} / \sqrt{\mathrm{Pa}})\end{array}$ & $\begin{array}{l}3.04 \exp \frac{-5.47(\mathrm{~kJ} / \mathrm{mol})}{R T / 1}[1]^{3} \\
3.73 \exp \frac{-6.86(\mathrm{~kJ} / \mathrm{mol})}{R T}[47]\end{array}$ & 0.35 & 0.50 & 0.75 \\
\hline
\end{tabular}

${ }^{1}$ AL 29-4-2 ferritic stainless steel; ${ }^{2}$ This study; ${ }^{3}$ AISI 310 ASS.

According to local equilibrium assumption of hydrogen between BCC and FCC phase, we have

$$
c_{\mathrm{sfcc}} \exp \left(-E_{\mathrm{Bfcc}} / R T\right)=c_{\mathrm{sbcc}} \exp \left(-E_{\mathrm{Bbcc}} / R T\right)
$$

In general, $E_{\mathrm{Bfcc}}$ has a value of $13.5 \mathrm{~kJ}[54]$ and $E_{\mathrm{Bbcc}}$ has $27 \mathrm{~kJ}[55]$ at $20^{\circ} \mathrm{C}$. Inserting 13.5 and $27 \mathrm{~kJ}$ into Equation (17), we get $c_{\mathrm{sfcc}} / c_{\mathrm{sbcc}}=224$, which is close to the value that can be calculated from the data in Table 2, e.g., $c_{\mathrm{sfcc}} / c_{\mathrm{sbcc}}=0.35 / 0.002=175$. Inserting Equation (17) into Equation (16), we can get $\log D_{\mathrm{app}}=\log D_{\mathrm{bcc}} c_{\mathrm{bcc}} / c_{\mathrm{fcc}}+\log f_{\mathrm{bcc}} /\left(1-f_{\mathrm{bcc}}\right)$. Therefore, linear relation between $\log D_{\text {app }}$ and $\log \left[f_{\mathrm{bcc}} /\left(1-f_{\mathrm{bcc}}\right)\right]$ can also be deduced from the viewpoint of hydrogen trapping. It is interesting that both Equations (10)-(15) can lead to Equation (13), though the former is based on the geometrical configuration whereas the latter is based on the hydrogen trapping role of $\gamma$ platelets.

Figures $11 \mathrm{~d}$ and 13 plots experimental $c_{\text {sapp }}$ and $D_{\text {app }}$ as a function of $f_{\alpha^{\prime}}$, respectively. $\log D_{\text {app }}$ linearly increases with $\log \left[f_{\alpha^{\prime}} /\left(1-f_{\alpha^{\prime}}\right)\right]$ when $f_{\alpha^{\prime}}>2 \%$ and $c_{\text {app }}$ linearly decreases with $f_{\alpha^{\prime}}$. Thus, Equations (10)-(14) can be used to describe the apparent hydrogen diffusivity and solubility of $\alpha^{\prime}$-containing ASSs. To further valid Equations (10) and (13), Figure 14 shows a summary of experimental data available in literatures [1,2,50,56-69] including the typical duplex materials. Most of the experimental data follow a near-linear relation between $\log D_{\text {app }}$ and $\log \left[f_{\alpha^{\prime}} /\left(1-f_{\alpha^{\prime}}\right)\right]$. Moreover, by inserting the reported transport parameters listed in Table 2 into Equation (10), the diffusivities at a similar temperature were predicted. The predicting curves are very close to the reported data, Figure 14.

Nevertheless, the series model Equation (11) cannot produce the linear trend of $\log D_{\text {app }}$ as a function of $\log \left[f_{\alpha^{\prime}} /\left(1-f_{\alpha^{\prime}}\right)\right]$, Figure 14. Some researchers have also suggested relations to describe the apparent hydrogen diffusivity of duplex materials. For instance, Equation (18) is another simple series model used by Iacoviello et al. [69,70], Equation (19) is the model used by Bernabai and Torella [71], Hsu et al. [72], and He et al. [62]. These two models do not include solubility item. Equation (20) is the model extracted from the study of Turnbull and Hutchings [47] and, for example, has been used by Silva et al. [61].

$$
\frac{1}{D_{\mathrm{app}}}=\frac{f_{\mathrm{bcc}}}{D_{\mathrm{bcc}}}+\frac{f_{\mathrm{fcc}}}{D_{\mathrm{fcc}}}
$$




$$
\begin{gathered}
D_{\text {app }}=\frac{D_{\gamma} D_{\alpha}}{f_{\gamma}^{2} D_{\alpha}+f_{\alpha}^{2} D_{\gamma}} \\
D_{\mathrm{app}}=\frac{D_{\mathrm{bcc}} s_{\mathrm{bcc}}}{s_{\mathrm{fcc}}} \frac{6\left(1-f_{\mathrm{bcc}}\right)^{2}}{f_{\mathrm{bcc}}\left(1+f_{\mathrm{bcc}}\right)}
\end{gathered}
$$

Based on the data listed in Table 2, these models are also depicted in Figure 14. It can be found that these three equations cannot predict the diffusivity of duplex materials more accurately compared with Equations (10)-(13). Equations (10)-(13) are enough to assess quickly the diffusivity for a duplex material at hand when exact diffusion data are not available.

\subsection{FE Simulations}

Hydrogen transport in a duplex material depends on the size, shape, orientation, and geometrical configuration of FCC/BCC platelets. To study the effects of these factors, some studies have used FE method. Olden et al. [52] simulated the effects of shape, size, and orientation of $\gamma$ platelets in a ferrite-austenite steel. They revealed that FE method is applicable to demonstrate hydrogen transport in a duplex steel. Mente and Boellinghaus [73] have demonstrated hydrogen diffusion and effusion behaviors of a duplex steel consisting of $45 \% \gamma$ by FE method. They used a geometrical configuration copied from a real OM image. The fraction of BCC/FCC platelets also affects hydrogen diffusion; thus, we studied the effect of $\alpha^{\prime}$ fraction on hydrogen diffusion of prestrained 304L steel by FE method.

Olden et al. assume a regular arrangement for $\gamma$ platelets [52], but the embedded platelets of a duplex material are generally distributed randomly and some platelets connected with each other. For the prestrained 304L steel, Figures 3 and $4 \mathrm{~d}$ also indicates that $\alpha^{\prime}$ platelets distributed somewhat randomly. Thus, duplex materials are more suitably modeled by means of representative volume element (RVE) method, which has been widely employed to predict the mechanical/thermal behavior of duplex steels or composites [74,75]. Using ABAQUS 6.10 software (SIMULIA, Providence, RI, USA), 2D RVE models were built for 304L steel. Based on Figures 3 and $4 \mathrm{~d}$, the embedded $\alpha^{\prime}$ platelets are modeled as squares for simplicity and they distribute randomly with a quantity equal to that of prior $\gamma$ gains. The $\alpha^{\prime}$ squares grow bigger with increasing prestrain, thus the size of $\alpha^{\prime}$ squares were set as $10,20,30,35,40,45$, and $48 \mu \mathrm{m}$ (prior $\gamma$ size is $50 \mu \mathrm{m}$ ), corresponding to a volume faction of $\alpha^{\prime}$ of 4,16 , $36,49,64,81$, and $92 \%$, respectively (for example, $(40 \times 40) /(50 \times 50)=64 \%)$. Figure 15 shows the model containing $64 \% \alpha^{\prime}$ as an example.

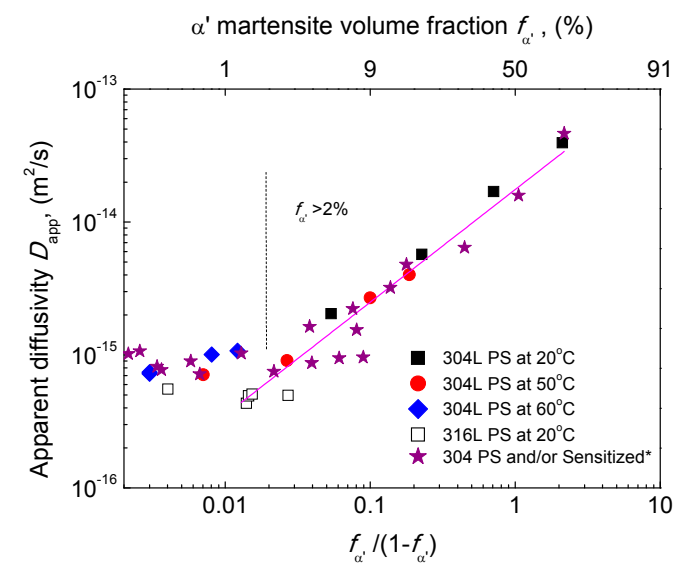

Figure 13. Relation between $\log D_{\text {app }}$ and $\log \left[f_{\alpha^{\prime}} /\left(1-f_{\alpha^{\prime}}\right)\right]$. $\quad\left({ }^{*}\right.$ : These data were obtained for a 304 steel in another ongoing study. The steel was firstly prestrained and then submitted to sensitization for different times to vary the content of pre-existing $\alpha^{\prime}$ ). 


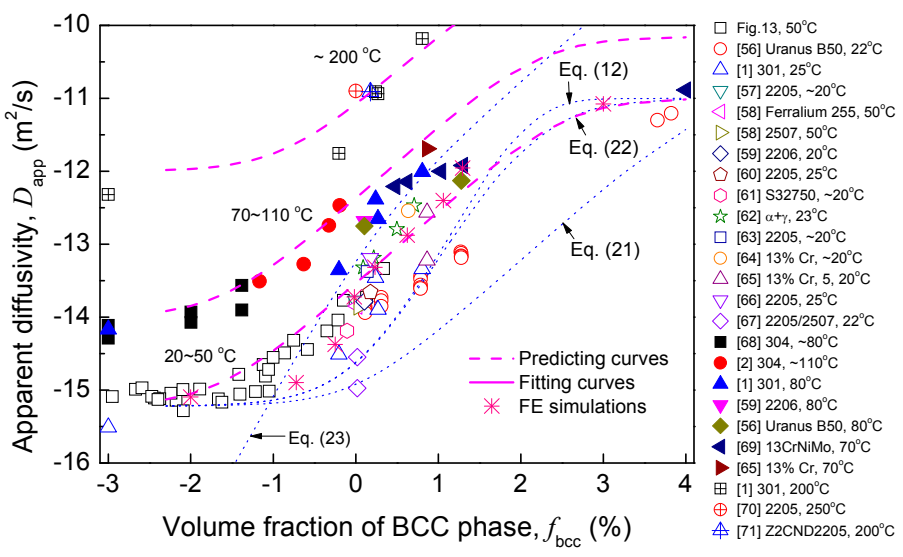

Figure 14. $D_{\text {app }}$ of FCC + BCC duplex materials reported as a function of BCC volume fraction.

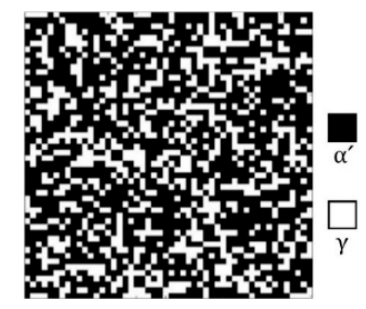

Figure 15. 2D RVE model of the 304L steel containing $64 \% \alpha^{\prime}$.

The diffusion calculation of ABAQUS is based on an extension of Fick's equation allowing for the nonuniform solubility of hydrogen in a material. The basic solution variable is the so-called "normalized concentration", denoted as $\varphi, \varphi=c / s$. The diffusion constitutive equation is

$$
\frac{\mathrm{d} \varphi}{\mathrm{d} t}=D \nabla^{2} \varphi
$$

The diffusivity and solubility parameters at $20-50{ }^{\circ} \mathrm{C}$ listed in Table 2 are assigned to the $\alpha^{\prime}$ and $\gamma$ phase regions. A constant surface normalized concentration is prescribed on the top surface as the diffusion boundary condition.

Figures 16 and 17 show the contour results obtained by ABAQUS. Hydrogen transport depth increases with time, Figure 16a,b. The presence of $\alpha^{\prime}$ platelets significantly accelerates the hydrogen transport, as indicated by Figure $16 \mathrm{~b}, \mathrm{c}$. If the $\alpha^{\prime}$ squares connect with each other into a path along depth direction, the acceleration is more significant, as indicated by location a, b, and c in Figure 16e, where diffusion "highways" can be traced out along the connected $\alpha^{\prime}$ squares and the transport path is crooked. The magnitude of concentration flux vector of hydrogen, $M_{\text {flux }}$, is very large along the connected $\alpha^{\prime}$ squares, Figure 16f, demonstrating directly the "highways" role of connected $\alpha^{\prime}$ platelets in hydrogen transport. However, if the $\alpha^{\prime}$ squares are surrounded by $\gamma$ platelets, the transport rate is somewhat small, as indicated by location e in Figure 16e. Figure 16d shows the result of a case where all $\alpha^{\prime}$ squares are surrounded by $\gamma$ phase, similar with the cases considered by Olden et al. [52], where the $\alpha^{\prime}$ squares are all embedded in $\gamma$ phase and are arranged regularly rather than randomly. Evidently, this case results in a lower transport depth. Thus, it may be not suitable for a duplex material with irregularly distributed embedded platelets, such as the prestrained and $\alpha^{\prime}$-containing 304L steel. Moreover, at the same time, hydrogen transport depth increases with volume fraction of $\alpha^{\prime}$, Figure 17.

$D_{\text {app }}$ was calculated by substituting the average concentration at a certain depth into Equation (4) according to Olden et al. [52], Figure 14. When $35 \%<f_{\alpha^{\prime}}<90 \%$, the simulated results are close to experimental data, it seems that there is also a linear relation between $\log D_{\text {app }}$ and $\log \left[f_{\alpha^{\prime}} /\left(1-f_{\alpha^{\prime}}\right)\right]$. 
However, when $f_{\alpha^{\prime}}<35 \%$ the FE simulated data are lower. This is probably because at the early stage of plastic deformation, the small $\alpha^{\prime}$ platelets mainly nucleate and grow within the shear bands, thus at this stage $\alpha^{\prime}$ phase should be modeled as lines or mesh rather than squares. Evidently, for a specified content of $\alpha^{\prime}$, the $\alpha^{\prime}$ lines or mesh can transport hydrogen faster.

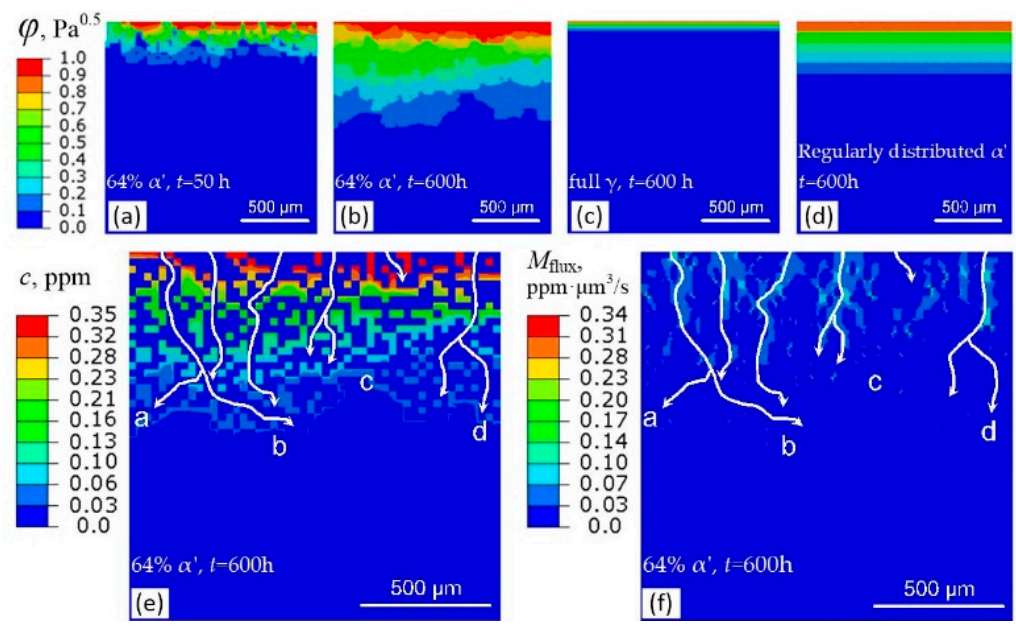

Figure 16. Contour results obtained by ABAQUS. (a-d) Normalized hydrogen concentration, $\varphi$; (e) hydrogen concentration, c; (f) magnitude of the concentration flux vector of hydrogen, Mflux. The white lines with arrows in $(\mathbf{e}, \mathbf{f})$ represent the hydrogen diffusion path. The locations, where $\alpha^{\prime}$ squares connect with each other to form a path, i.e., (a-d), show the role of $\alpha^{\prime}$ as diffusion "highways".
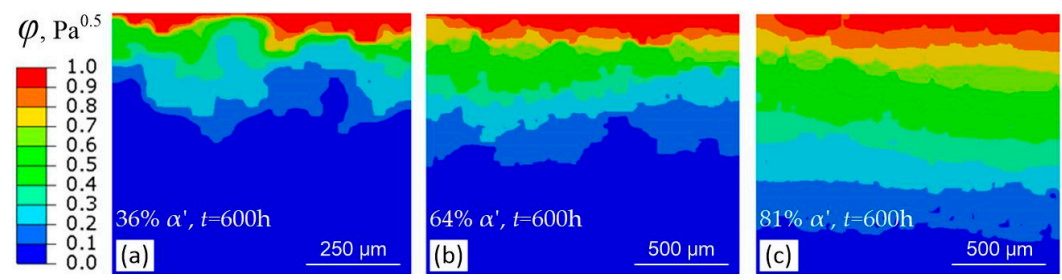

Figure 17. Normalized concentration distributions after $600 \mathrm{~h}$ diffusion at different $\alpha^{\prime}$ volume fractions: (a) $36 \%$ vol. $\alpha^{\prime}$; (b) $64 \%$ vol. $\alpha^{\prime}$; (c) $81 \%$ vol. $\alpha^{\prime}$.

\section{Conclusions}

The effects of microstructural changes induced by prestraining on the HE of 304L and 316L steels were investigated. The conclusions are as follows:

1. Room temperature prestrains higher than $20 \%$ can significantly increase the HE degree of $304 \mathrm{~L}$ steel after hydrogen exposure, because they can induce severe $\alpha^{\prime}$ transformation. During hydrogen exposure, the pre-existing $\alpha^{\prime}$ platelets, acting as hydrogen diffusion "highways", increase significantly the hydrogen transport, thus increasing the HE degree.

2. $304 \mathrm{~L}$ steel prestrained at higher temperatures $\left(50\right.$ and $\left.80{ }^{\circ} \mathrm{C}\right)$ and $316 \mathrm{~L}$ steel prestrained at $20^{\circ} \mathrm{C}$ exhibit more dislocations but much less $\alpha^{\prime}$ after prestraining, consequently their HE degree and hydrogen diffusivity are just slightly increased by prestraining. HEE can be enhanced by the increase of dislocations after prestraining by transporting more hydrogen into the steel during concurrent loading and hydrogen exposure. However, in the IHE condition studied, where no macroscopic plastic deformation occurs during hydrogen exposure, hydrogen entry is mainly enhanced by $\alpha^{\prime}$ "highways" rather than by dislocations. The increase of dislocations has a negligible influence on the apparent hydrogen diffusivity, as compared with the pre-existing $\alpha^{\prime}$. 
3. Deformation twins can provide easier cracking paths for HE, it can assist IG fracture in the heavily prestrained 304L steel after hydrogenation. The fracture surfaces of heavily prestrained and hydrogenated 304L steel show many flat facets and intergranular (IG) fracture.

4. Warm prestrains result in much less $\alpha^{\prime}$ but they can still strengthen the 304L steel by a large degree, thus there is a potential to use warm prestrains to strengthen the metastable ASSs without compromising their HE resistance.

5. The heavily prestrained metastable 304L steel can be considered a duplex material. With increasing $\alpha^{\prime}$ platelets, the apparent hydrogen diffusivity of steel increases but its solubility decreases. The apparent hydrogen diffusivity and solubility can be described quantitatively by the parallel configuration model or by the following relations:

$$
\left\{\begin{array}{l}
\log D_{\text {app }}=\log \frac{D_{\alpha^{\prime}} s_{\alpha^{\prime}}}{s_{\gamma}}+\log \left(\frac{f_{\alpha^{\prime}}}{1-f_{\alpha^{\prime}}}\right) \\
s_{\text {app }}=s_{\gamma}\left(1-f_{\alpha^{\prime}}\right)
\end{array}\right.
$$

There two relations can be also applied the other more typical duplex materials.

Author Contributions: Conceptualization, Y.W.; Methodology, Y.W., X.W., and W.W.; Investigation, Y.W., X.W. and W.W.; Data curation, X.W. and W.W.; Resources, Y.W.; Supervision, Y.W.; Writing-original draft, X.W.; Writing-review \& editing, Y.W.

Funding: This research was funded by the Fundamental Research Funds for the Central Universities of China (Grant No. 2015QNA20).

Acknowledgments: The authors thank J.G. (Nanjing Tech University) for his technical assistance and acknowledge the financial support by the Fundamental Research Funds for the Central Universities of China (2015QNA20).

Conflicts of Interest: The authors declare no conflicts of interest. The funders had no role in the design of the study; in the collection, analyzes, or interpretation of data; in the writing of the manuscript, and in the decision to publish the results.

\section{References}

1. Perng, T.P.; Altstetter, C.J. Effects of deformation on hydrogen permeation in austenitic stainless steels. Acta Metall. 1986, 34, 1771-1781.

2. Mine, Y.; Narazaki, C.; Murakami, K.; Matsuoka, S.; Murakami, Y. Hydrogen transport in solution-treated and pre-strained austenitic stainless steels and its role in hydrogen-enhanced fatigue crack growth. Int. J. Hydrogen Energy 2009, 34, 1097-1107. [CrossRef]

3. Martin, M.; Weber, S.; Izawa, C.; Wagner, S.; Pundt, A.; Theisen, W. Influence of machining-induced martensite on hydrogen-assisted fracture of AISI type 304 austenitic stainless steel. Int. J. Hydrogen Energy 2011, 36, 11195-11206. [CrossRef]

4. Wang, Y.; Wang, X.; Gong, J.; Shen, L.; Dong, W. Hydrogen embrittlement of catholically hydrogenprecharged 304L austenitic stainless steel: Effect of plastic pre-strain. Int. J. Hydrogen Energy 2014, 39, 13909-13918. [CrossRef]

5. Buckley, J.R.; Hardie, D. The effect of pre-straining and $\delta$-ferrite on the embrittlement of 304L stainless steel by hydrogen. Corros. Sci. 1993, 34, 93-107. [CrossRef]

6. Perng, T.P.; Altstetter, C.J. Cracking kinetics of two-phase stainless steel alloys in hydrogen gas. Metall. Trans. A 1988, 19, 145-152. [CrossRef]

7. Zhang, L.; Li, Z.; Zheng, J.; Zhao, Y.; Xu, P.; Zhou, C.; Li, X. Effect of strain-induced martensite on hydrogen embrittlement of austenitic stainless steels investigated by combined tension and hydrogen release methods. Int. J. Hydrogen Energy 2013, 38, 8208-8214. [CrossRef]

8. Zhang, L.; Li, Z.; Zheng, J.; Zhao, Y.; Xu, P.; Liu, X. Influence of low temperature prestrain on hydrogen gas embrittlement of metastable austenitic stainless steels. Int. J. Hydrogen Energy 2013, 38, 11181-11187. [CrossRef] 
9. Chen, X.; Zhou, C.; Zheng, J.; Zhang, L. Effects of $\alpha^{\prime}$ martensite and deformation twin on hydrogen-assisted fatigue crack growth in cold/warm-rolled type 304 stainless steel. Int. J. Hydrogen Energy 2018, 43, 3342-3352. [CrossRef]

10. Lai, C.L.; Tsay, L.W.; Chen, C. Effect of microstructure on hydrogen embrittlement of various stainless steels. Mater. Sci. Eng. A 2013, 584, 14-20. [CrossRef]

11. Chen, T.C.; Chen, S.T.; Tasy, L.W. The role of induced $\alpha^{\prime}$-martensite on the hydrogen-assisted fatigue crack growth of austenitic stainless steels. Int. J. Hydrogen Energy 2014, 39, 10293-10302. [CrossRef]

12. Choo, W.Y.; Lee, J.Y. Effect of cold working on the hydrogen trapping phenomena in pure iron. Metall. Trans. A 1983, 14, 1299-1305. [CrossRef]

13. Huang, Y.; Nakajim, A.; Nishikata, A.; Tsuru, T. Effect of mechanical deformation on permeation of hydrogen in iron. ISIJ Int. 2003, 43, 548-554. [CrossRef]

14. Michler, T.; Naumann, J.; Hock, M.; Berreth, K.; Balogh, M.P.; Sattler, E. Microstructural properties controlling hydrogen environment embrittlement of cold worked 316 type austenitic stainless steels. Mater. Sci. Eng. A 2015, 628, 252-261. [CrossRef]

15. Louthan, M.R., Jr.; Caskey, G.R., Jr.; Donovan, J.A.; Rawl, D.E., Jr. Hydrogen embrittlement of metals. Mater. Sci. Eng. 1972, 10, 357-368. [CrossRef]

16. Koyama, M.; Akiyama, E.; Sawaguchi, T.; Raabe, D.; Tsuzaki, K. Hydrogen-induced cracking at grain and twin boundaries in an Fe-Mn-C austenitic steel. Scr. Mater. 2012, 66, 459-462. [CrossRef]

17. Koyama, M.; Akiyama, E.; Tsuzaki, K.; Raabe, D. Hydrogen-assisted failure in a twinning-induced plasticity steel studied under in situ hydrogen charging by electron channeling contrast imaging. Acta Mater. 2013, 61, 4607-4618. [CrossRef]

18. Koyama, M.; Akiyama, E.; Tsuzaki, K. Hydrogen embrittlement in a Fe-Mn-C ternary twinning-induced plasticity steel. Corros. Sci. 2012, 54, 1-4. [CrossRef]

19. Caskey, G.R., Jr. The role of twinning and transformation in hydrogen embrittlement of austenitic stainless steels. In Proceedings of the Conference of the Environmental Degradation of Engineering Materials, Blacksburg, VA, USA, 10 October 1977.

20. Caskey, G.R., Jr. Fractography of hydrogen-embrittled iron-chromium-nickel alloys. In Proceedings of the 13th Annual Technical Meeting of the International Metallographic Society, Brighton, UK, 18-20 August 1980.

21. Eliezer, D.; Chakrapani, D.G.; Altstetter, C.J.; Pugh, E.N. The influence of austenite stability on the hydrogen embrittlement and stress-corrosion cracking of stainless steel. Metall. Trans. A 1979, 10, 935-941. [CrossRef]

22. Ji, H.; Park, I.J.; Lee, S.M.; Lee, Y.K. The effect of pre-strain on hydrogen embrittlement in $310 \mathrm{~S}$ stainless steel. J. Alloys Compd. 2014, 598, 205-212. [CrossRef]

23. Park, I.J.; Jung, J.G.; Jo, S.Y.; Lee, S.M.; Lee, Y.K. The effect of pre-strain on the resistance to hydrogen embrittlement in 316L austenitic stainless steel. Mater. Trans. 2014, 55, 964-970. [CrossRef]

24. Talonen, J.; Hänninen, H. Formation of shear bands and strain-induced martensite during plastic deformation of metastable austenitic stainless steels. Acta Mater. 2007, 55, 6108-6118. [CrossRef]

25. Ahmedabadi, P.M.; Kain, V.; Agrawal, A. Modelling kinetics of strain-induced martensite transformation during plastic deformation of austenitic stainless steel. Mater. Des. 2016, 109, 466-475. [CrossRef]

26. Shin, H.C.; Ha, T.K.; Chang, Y.W. Kinetics of deformation induced martensitic transformation in a 304 stainless steel. Scr. Mater. 2001, 45, 823-829. [CrossRef]

27. Nohara, K.; Ono, Y.; Ohashi, N. Composition and grain size dependencies of strain-induced martensitic transformation in metastable austenitic stainless steels. Tetsu-to-Hagane 1977, 63, 212-222. [CrossRef]

28. ASTM International. Metallography, Nondestructive Testing; ASTM International: New York, NY, USA, 1986; pp. 115-117.

29. Wu, Z.; Huang, Y. Mechanical behavior and fatigue performance of austenitic stainless steel under consideration of martensitic phase transformation. Mater. Sci. Eng. A 2017, 679, 249-257.

30. Tian, Y.; Gorbatov, O.I.; Borgenstam, A.; Ruban, A.V.; Hedström, P. Deformation microstructure and deformation-induced martensite in austenitic Fe-Cr-Ni alloys depending on stacking fault energy. Metall. Mater. Trans. A 2017, 48, 1-7. [CrossRef]

31. Ahmadzade-Beiraki, E.; Mazinani, M.; Kashefi, M. Examination of Barkhausen noise parameters for characterisation of strain-induced martensitic transformation in AISI 304 stainless steel. Insight 2016, 58, 297-301. [CrossRef] 
32. Mirzadeh, H.; Cabrera, J.M.; Najafizadeh, A.; Calvillo, P.R. EBSD study of a hot deformed austenitic stainless steel. Mater. Sci. Eng. A 2012, 538, 236-245. [CrossRef]

33. Cullity, B.D. Elements of X-ray Diffraction; Addison-Wesley: Reading MA, USA, 1978; pp. $392-393$.

34. De, A.K.; Murdock, D.C.; Mataya, M.C.; Speer, J.G.; Matlock, D.K. Quantitative measurement of deformation-induced martensite in 304 stainless steel by X-ray diffraction. Scr. Mater. 2004, 50, 1445-1449. [CrossRef]

35. Williamson, G.K.; Smallman, R.E. Dislocation densities in some annealed and cold-worked metals from measurements on the X-ray Debye-Scherrer spectrum. Philos. Mag. 1955, 1, 34-36. [CrossRef]

36. Dini, G.; Ueji, R.; Najafizadeh, A.; Monir-Vaghefi, S.M. Flow stress analysis of TWIP steel via the XRD measurement of dislocation density. Mater. Sci. Eng. A 2010, 527, 2759-2763. [CrossRef]

37. Peng, Y.; Gong, J.; Jiang, Y.; Fu, M.; Rong, D. The effect of plastic pre-strain on low-temperature surface carburization of AISI 304 austenitic stainless steel. Surf. Coat. Technol. 2016, 304, 16-22. [CrossRef]

38. Steel and Iron-Determination of Hydrogen Content_Inert Gas Impulse Fusion Heat Conductivity Method; SAC: Beijing, China, 2007; GB/T 223.82-2007.

39. Olson, G.B.; Cohen, M. Kinetics of strain-induced martensitic nucleation. Metall. Trans. A 1975, 6, 791-795. [CrossRef]

40. Mishra, S.; Narasimhan, K.; Samajdar, I. Deformation twinning in AISI 316L austenitic stainless steel: role of strain and strain path. Mater. Sci. Technol. 2007, 23, 1118-1126. [CrossRef]

41. Shen, Y.F.; Li, X.X.; Sun, X.; Wang, Y.D.; Zuo, L. Twinning and martensite in a 304 austenitic stainless steel. Mater. Sci. Eng. A 2012, 552, 514-522. [CrossRef]

42. Shintani, T.; Murata, Y. Evaluation of the dislocation density and dislocation character in cold rolled Type 304 steel determined by profile analysis of X-ray diffraction. Acta Mater. 2011, 59, 4314-4322. [CrossRef]

43. Lebedev, A.A.; Kosarchuk, V.V. Influence of phase transformations on the mechanical properties of austenitic stainless steels. Int. J. Plast. 2000, 16, 749-767. [CrossRef]

44. Olden, V.; Thaulow, C.; Johnsen, R. Modelling of hydrogen diffusion and hydrogen induced cracking in supermartensitic and duplex stainless steels. Mater. Des. 2008, 29, 1934-1948. [CrossRef]

45. Crank, J. The Mathematics of Diffusion; Oxford University Press: Clarendon, UK, 1975; pp. 231-232.

46. Zhu, W.Y.; Qiao, L.J.; Li, J.X.; Su, Y.J.; Yan, Y.; Bai, Y.; Ren, X.C.; Huang, H.Y. Hydrogen Embrittlement and Stress Corrosion Cracking; Science Press: Beijing, China, 2013; p. 124.

47. Turnbull, A.; Hutchings, R.B. Analysis of hydrogen atom transport in a two-phase alloy. Mater. Sci. Eng. A 1994, 177, 161-171. [CrossRef]

48. Walter, R.J.; Jewett, R.P.; Chandler, W.T. On the mechanism of hydrogen-environment embrittlement of ironand nickel-base alloys. Mater. Sci. Eng. 1970, 5, 99-110. [CrossRef]

49. West, A.J.; Louthan, M.R. Dislocation Transport and Hydrogen Embrittlement. Metall. Trans. A 1979, 10, 1675-1682. [CrossRef]

50. Gesnouin, C.; Hazarabedian, A.; Bruzzoni, P.; Ovejero-García, J.; Bilmes, P.; Llorente, C. Effect of post-weld heat treatment on the microstructure and hydrogen permeation of $13 \mathrm{CrNiMo}$ steels. Corros. Sci. 2004, 46, 1633-1647. [CrossRef]

51. Owczarek, E.; Zakroczymski, T. Hydrogen transport in a duplex stainless steel. Acta Mater. 2000, 48, 3059-3070. [CrossRef]

52. Olden, V.; Saai, A.; Jemblie, L.; Johnsen, R. FE simulation of hydrogen diffusion in duplex stainless steel. Int. J. Hydrogen Energy 2014, 39, 1156-1163. [CrossRef]

53. Oriani, R.A. The diffusion and trapping of hydrogen in steel. Acta Metall. 1970, 18, 147-157. [CrossRef]

54. Thomas, G.J. Hydrogen trapping in fcc metals. In Proceedings of the Conference of Hydrogen Effects in Metals, Jackson Lake Lodge, WY, USA, 26-31 August 1980; pp. 77-85.

55. Hagi, H.; Hayashi, Y. Effects of interstitial impurities on dislocation trapping on hydrogen in iron. Trans. Jpn. Inst. Met. 1987, 28, 375-382. [CrossRef]

56. Hutchings, R.B.; Turnbull, A.; May, A.T. Measurement of hydrogen transport in a duplex stainless steel. Scr. Metall. Mater. 1991, 25, 2657-2662. [CrossRef]

57. Sentence, P. Hydrogen embrittlement of cold worked duplex stainless steel oilfield tubulars. In Proceedings of the Conference of Duplex Stainless Steel 91, Beaune, France, 28-30 October 1991; Volume 2, pp. 895-903.

58. Alsarraf, J. Hydrogen Embrittlement Susceptibility of Super Duplex Stainless Steels. Ph.D Thesis, Cranfield University, Bedfordshire, UK, 2010. 
59. Wang, X.G.; Dumortier, D.; Riquier, Y. Structural evolution of zeron 100 duplex stainless steel between 550 nd $1100{ }^{\circ} \mathrm{C}$. In Proceedings of the Conference of Duplex Stainless Steel 91, Beaune, France, 28-30 October 1991; Volume 1, pp. 127-134.

60. Chen, S.S.; Wu, T.I.; Wu, J.K. Effects of deformation on hydrogen degradation in a duplex stainless steel. J. Mater. Sci. 2004, 39, 67-71. [CrossRef]

61. da Silva, B.R.S.; Salvio, F.; dos Santos, D.S. Hydrogen embrittlement in super duplex stainless steel tubes UNS S32750 under mechanical stress. In Proceedings of the 2012 International Hydrogen Conference on Hydrogen-Materials Interactions, Jackson Lack Lodge, WY, USA, 9-12 September 2012; pp. 245-254.

62. He, J.; Tang, X.; Chen, N. Diffusion of hydrogen in $(\alpha+\gamma)$ duplex stainless steel. Acta Metall. Sin. 1989, 25, 42-47.

63. Chou, S.L.; Tsai, W.T. Effect of grain size on the hydrogen-assisted cracking in duplex stainless steels. Mater. Sci. Eng. A 1999, 270, 219-224. [CrossRef]

64. Smirnova, A.; Johnsen, R. Effect of Tensile Stress on Hydrogen Permeation in 13\% Cr Super Martensitic Stainless Steel. Available online: https:/ / brage.bibsys.no/xmlui/bitstream/handle/11250/248888/506367_ FULLTEXT01.pdf?sequence=1 (accessed on 8 June 2018).

65. Hinds, G.; Zhao, J.; Griffiths, A.J.; Turnbull, A. Hydrogen diffusion in Super 13\% chromium martensitic stainless steel. Corrosion 2005, 61, 348-354. [CrossRef]

66. Luu, W.C.; Liu, P.W.; Wu, J.K. Hydrogen transport and degradation of a commercial duplex stainless steel. Corros. Sci. 2002, 44, 1783-1791. [CrossRef]

67. Turnbull, A.; Beylegaard, E.L.; Hutchings, R.B. Hydrogen transport in SAF 2205 and SAF 2507 duplex stainless steels. In Proceedings of the Conference of Hydrogen Transport and Cracking in Metals, Cambridge, UK, 13-14 April 1994; pp. 268-279.

68. Dayal, R.K.; Grabke, H.K. Dependence of the hydrogen permeation in stainless steel on carbon content, heat treatment and cold work. Steel Res. 2000, 71, 255-260. [CrossRef]

69. Iacoviello, F.; Habashi, M.; Cavallini, M. Hydrogen embrittlement in the duplex stainless steel Z2CND2205 hydrogen-charged at $200^{\circ}$ C. Mater. Sci. Eng. A 1997, 224, 116-124. [CrossRef]

70. Iacoviello, F.; Galland, J.; Habashi, M. A thermal outgassing method (T.O.M.) to measure the hydrogen diffusion coefficients in austenitic, austeno-ferritic and ferritic-perlitic steels. Corros. Sci. 1998, 40, 1281-1293. [CrossRef]

71. Bernabai, U.; Torella, R. Thermal analysis of hydrogen-charged austenitic and duplex stainless steels. Int. J. Hydrogen Energy 1993, 18, 763-771. [CrossRef]

72. Hsu, J.W.; Tsai, S.Y.; Shih, H.C. Hydrogen Embrittlement of SAF 2205 Duplex Stainless Steel. Corrosion 2002, 58, 858-862. [CrossRef]

73. Mente, T.; Boellinghaus, T. Modeling of hydrogen distribution in a duplex stainless steel. Weld. World 2012, 56, 66-78. [CrossRef]

74. Paul, S.K. Micromechanics based modeling of dual phase steels: Prediction of ductility and failure modes. Comput. Mater. Sci. 2012, 56, 34-42. [CrossRef]

75. Sun, C.T.; Vaidya, R.S. Prediction of composite properties from a representative volume element. Compos. Sci. Technol. 1996, 56, 171-179. [CrossRef]

(C) 2018 by the authors. Licensee MDPI, Basel, Switzerland. This article is an open access article distributed under the terms and conditions of the Creative Commons Attribution (CC BY) license (http://creativecommons.org/licenses/by/4.0/). 